NBER WORKING PAPER SERIES

\title{
WILL CHINA EAT OUR LUNCH OR TAKE US OUT TO DINNER? SIMULATING THE TRANSITION PATHS OF THE U.S., EU, JAPAN, AND CHINA
}

\author{
Hans Fehr \\ Sabine Jokisch \\ Laurence J. Kotlikoff \\ Working Paper 11668 \\ http://www.nber.org/papers/w11668 \\ NATIONAL BUREAU OF ECONOMIC RESEARCH \\ 1050 Massachusetts Avenue \\ Cambridge, MA 02138 \\ September 2005
}

We thank Charles Horioka, Bernd Ra.elhuschen, and Reinhold Schnabel for providing key data. Research support by the U.S. Social Security Administration, Boston University, the Deutsche Forschungsgemeinschaft, and the Universitatsbund Wuerzburg is gratefully acknowledged. The views expressed herein are those of the author(s) and do not necessarily reflect the views of the National Bureau of Economic Research.

(C2005 by Hans Fehr, Sabine Jokisch and Laurence J. Kotlikoff. All rights reserved. Short sections of text, not to exceed two paragraphs, may be quoted without explicit permission provided that full credit, including (C) notice, is given to the source. 
Will China Eat Our Lunch or Take Us Out to Dinner? Simulating the Transition Paths of the U.S., EU, Japan, and China

Hans Fehr, Sabine Jokisch and Laurence J. Kotlikoff

NBER Working Paper No. 11668

September 2005

JEL No. E2, E4, H2, H3, H5, H6, J1

\section{$\underline{\text { ABSTRACT }}$}

This paper develops a dynamic, life-cycle, general equilibrium model to study the interdependent demographic, fiscal, and economic transition paths of China, Japan, the U.S., and the EU. Each of these countries/regions is entering a period of rapid and significant aging requiring major fiscal adjustments.

In previous studies that excluded China we predicted that tax hikes needed to pay benefits along the developed world's demographic transition would lead to capital shortage, reducing real wages per unit of human capital. Adding China to the model dramatically alters this prediction. Even though China is aging rapidly, its saving behavior, growth rate, and fiscal policies are very different from those of developed countries. If this continues to be the case, the model's long run looks much brighter.

China eventually becomes the world's saver and, thereby, the developed world's savoir with respect to its long-run supply of capital and long-run general equilibrium prospects. And, rather than seeing the real wage per unit of human capital fall, the West and Japan see it rise by one fifth by 2030 and by three fifths by 2100 . These wage increases are over and above those associated with technical progress.

Hans Fehr

University of Wuerzburg Institute of Economics

Sanderring 2

D-97070 Wuerzburg

GERMANY

hans.fehr@mail.uniwuerzburg.de
Sabine Jokisch Zentrum für Europäische Wirtschaftsforschung L 7 . 1

D-68161 Mannheim GERMANY

jokisch@zew.de
Laurence J. Kotlikoff Department of Economics Boston University 270 Bay State Road Boston, MA 02215 and NBER kotlikoff@bu.edu 


\begin{abstract}
This paper develops a dynamic, life-cycle, general equilibrium model to study the interdependent demographic, fiscal, and economic transition paths of China, Japan, the U.S., and the EU. Each of these countries/regions is entering a period of rapid and significant aging that will require major fiscal adjustments. But the aging of these societies may be a cloud with a silver lining coming, in this case, in the form of capital deepening that will raise real wages.

In a previous model that excluded China we predicted that tax hikes needed to pay benefits along the developed world's demographic transition would lead to a major capital shortage, reducing real wages per unit of human capital over time by one fifth. A recalibration of our original model that treats government purchases of capital goods as investment rather than current consumption suggests this concern was overstated. With government investment included, we find much less crowding out over the course of the century and only a 4 percent long-run decline in real wages.
\end{abstract}

Adding China to the model further alters, indeed, dramatically alters, the model's predictions. Even though China is aging rapidly, its saving behavior, growth rate, and fiscal policies are currently very different from those of developed countries. If successive cohorts of Chinese continue to save like current cohorts, if the Chinese government can restrain growth in expenditures, and if Chinese technology and education levels ultimately catch up with those of the West and Japan, the model's long run looks much brighter. China eventually becomes the world's saver and, thereby, the developed world's savoir with respect to its long-run supply of capital and long-run general equilibrium prospects. And, rather than seeing the real wage per unit of human capital fall, the West and Japan see it rise by one fifth percent by 2030 and by three fifths by 2100 . These wage increases are over and above those associated with technical progress, which we model as increasing the human capital endowments of successive cohorts.

Even if the Chinese saving behavior (captured by its time preference rate) gradually approaches that of Americans, developed world real wages per unit of human capital are roughly 17 percent higher in 2030 and 4 percent higher at the end of the century. Without China they'd be only 2 percent higher in 2030 and, as mentioned, 4 percent lower at Century's end. 
What's more, the major short-run outflow of the developed world's capital to China predicted by our model does not come at the cost of lower wages in the developed world. The reason is that the knowledge that their future wages will be higher (thanks to China's future capital accumulation) leads our model's workers to cut back on their current labor supply. So the shortrun outflow of capital to China is met with a commensurate short-run reduction in developed world labor supply, leaving the short-run ratio of physical capital to human capital, on which wages positively depend, actually somewhat higher than would otherwise be the case.

Our model does not capture the endogenous determination of skill premiums studied by Heckman and Taber (1996). Doing so could well show that trade with China, at least in the short run, explains much of the relative decline in the wages of low-skilled workers in the developed world. Hence, we don't mean to suggest here that all US, EU, and Japanese workers are being helped by trade with China, but rather that trade with China is, on average, raising the wages of developed world workers and will continue to do so.

The notion that China, India, and other developing countries will alleviate the developed world's demographic problems has been stressed by Siegel (2005). Our paper, although it includes only one developing country - China - supports Siegel's optimistic long-term macroeconomic view. On the other hand, our findings about the developed world's fiscal condition are quite troubling. Even under the most favorable macroeconomic scenario, tax rates will rise dramatically over time in the developed world to pay baby boomers their government-promised pension and health benefits. As Argentina has so recently shown, countries can grow quite well for years even with unsustainable fiscal policies. But if they wait too long to address those policies, the financial markets will do it for them, with often quite ruinous consequences. 


\section{Introduction}

This paper develops a dynamic, life-cycle, general equilibrium model to study the interdependent demographic, fiscal, and economic transition paths of China, Japan, the U.S., and the EU. Each of these countries/regions is entering a period of rapid and significant aging that will require major fiscal adjustments. Understanding how national aging and the fiscal reaction to national aging will affect the macro economies of these regions is important. If the macroeconomic response is favorable, governments can do less and take more time to deal with what's coming. If the opposite is true, governments must do more and do it more quickly.

Our past research (Fehr, Jokisch, and Kotlikoff (2004a,b, 2005) suggested an unfavorable macroeconomic response to national aging arising from a growing shortage of physical capital relative to human capital. This long-term capital shortage sufficed to reduce the model's real wage per unit of human capital by 20 percent over the course of the century. The model's predicted major decline in capital per unit of human capital connects to the model's predicted major rise in payroll and income tax rates. These tax hikes, in turn, reflect the need to pay pension and health care benefits to increasingly older populations. As originally stressed by Feldstein (1974), raising taxes on workers to make transfers to the elderly reduces the amount of capital workers individually and collectively can and will accumulate.

But our earlier studies, with their dismal forecasts that the interaction of aging and huge fiscal commitments to the elderly will undermine the macro economies of the developed world, omitted two issues. Both of these issues are taken up here, and both militate against a severe capital shortage.

The first is government investment. In our prior studies we treated all government purchases as current consumption. There is some logic for doing so, since many so-called government investment goods (e.g., tanks, office buildings to house bureaucrats, space vehicles) may make little or no contribution to the nation's output and productivity and, indeed, may do the opposite. On the other hand,the lion's share of government investment, be it in constructing roads, erecting schools, building research labs, does seem to be productive.

Treating what governments call investment as investment in the model doesn't entirely elim- 
inate the predicted long-term capital shortage, but it does significantly mitigate it. Compared with its 2004 value, the model's real wage per unit of human capital in 2100 is reduced by only 4 percent rather than by 20 percent.

The second omission is China. As everyone knows, China is already a major producer of world output. Its GDP now equals roughly one ninth of U.S. output. China is also absorbing Western and Japanese technology at a rapid clip. This acquisition of technology, in combination with improved education, holds the prospect for ongoing real income growth in China. But, given China's exceptionally high saving rate, more income growth in China means more Chinese saving that can be invested in the developed world as well as in China.

The potential for China and other developing countries to bail out the developed world, at least in terms of its capital needs, has recently been advanced by Jeremy Siegel (2005). But China has a long way to go if it is to play such a role. China's per capita income and wealth levels are currently only a small fraction - probably less than 15 percent - of the developed world's levels. Of course, China has lots of capitas - its population is 2.6 times the combined populations of the U.S., Japan, and the EU. Still, China's current total holdings of wealth appear to be less than one quarter and could be easily be less than one tenth of total wealth holdings across the four regions.

Moreover, Chinese saving behavior may change. It's certainly far from what one would expect to see. One would think that having low current income, but the prospect of much higher future income, would lead the Chinese to spend most of what they now produce. But, if official statistics are to be believed, nothing could be further from the truth. According to OECD (2002) data, the Chinese private sector appears to be saving 40.0 percent of private available output, defined as net national income minus government purchases of goods and services. This extraordinarily high Chinese private-sector saving rate explains why the Chinese are currently exporting more capital to the rest of the world than they are importing. Based on European Commission (2005) data, the comparable private-sector saving rates in the U.S., Japan, and EU are only 4.0 percent, 11.5 percent, and 11.1 percent, respectively.

China is also remarkable when it comes to aging. Like the developed world, China is getting older. But it's projected over the next half century to age much more rapidly than the U.S., 
Japan, or the EU. This doesn't mean that China will end up older than these regions. It just means it will make the transformation from a relatively young to a very old society much more rapidly than its trading partners in the developed world.

As Table 1 details, only 6.8 percent of today's Chinese are 65 and older compared with 17.2 percent in Japan, 16.4 percent in the EU, and 12.3 percent in the U.S. In 2050, 23.6 percent of the Chinese population will be 65 plus. This is larger than the 20.6 percent elderly share projected for the U.S., but smaller than the 28.6 and 35.9 percent shares projected in the EU and Japan, respectively. So the rapidity of China's aging doesn't reflect where it will end up, but where it is starting.

The fact that China, like Japan and the West,is aging and faces significant fiscal obligations associated with that process suggests that China's inclusion in our model would make little difference to the model's unpleasant prediction of a looming capital shortage. But because of China's much higher rates of growth and saving and because its population is so large, adding China can, as documented below, transform a capital shortage into a capital glut. Whether or not this occurs depends on how China's fiscal policy and saving behavior evolve. If, over the course of the next 50 years, China adopts fiscal arrangements and saving propensities that are similar to those of developing nations, China will make only a modest contribution to the world's supply of capital, leaving real wages per unit of human capital at the end of this century only about 4 percent higher than they are today. If, on the other hand, China limits growth in public expenditures and the Chinese people continue to eschew consumption, China will save enough for its own capital needs as well as those of the developed world, leaving real wages per unit of human capital at the end of this century roughly 60 percent above the current level.

The usefulness of these findings depends, of course, on the realism of our model. Our lifecycle model's features are a mouthful. The model includes age-, region-, and year-specific fertility and mortality rates, lifespan uncertainty, age-, region-, and year-specific pension, disability, health care, and other government transfer policies, region- and year-specific government purchases of goods and services, region-specific levels of debt, high, middle, and low earners within each cohort in each region, region-specific personal wage income, capital income, corporate income, and pay- 
roll taxes, international capital mobility, technological change, quadratic costs of adjusting each region's capital stock, age-specific inheritances, age-specific and unintended bequests, intertemporally separable CES utility functions in consumption and leisure, region-specific Cobb-Douglas production functions, the presence of children's utility in parents' utility functions when the children are young, exogenously specified age-, earnings class-, region-, and year-specific immigration, and region- and cohort-specific time preference rates.

As with our other three regions, to accommodate Chinese saving behavior, we've set the Chinese time preference rate to match the current observed saving rate for China. And we've calibrated the multifactor productivity coefficient in the Chinese production function to match the current observed Chinese relative wage. The big questions with respect to China's calibration, however, are not how to treat current saving preferences and technology, but rather how to model future saving preferences and technology.

Consider first the issue of technology. It seems reasonable to believe that the level of Chinese technology will converge to that of the West. The unknown is the rate of convergence. In this study we assume that the Chinese multi-factor productivity coefficient rises gradually, reaching the U.S., Japanese, and EU rates by mid century. But we also consider slower and faster rates of technological convergence.

Now consider modelling future Chinese saving behavior. Here we examine two alternative assumptions. The first is that the Chinese time preference rate remains fixed through time at the very low rate needed to calibrate the current Chinese saving rate. The second is that successive cohorts of Chinese gradually adopt Western saving behavior such that the Chinese born in 2050 and thereafter have the same time preference rate as Americans in 2004.

\section{Our Model and Its Predecessors}

The development of dynamic life-cycle simulation models was stimulated by Feldstein's (1974) article contending that government pension systems lower national saving. Early dynamic analysis of government pension programs and other policies include Kotlikoff (1979), Summers (1981), Auerbach and Kotlikoff (1983, 1987), and Seidman (1986). More recent papers have considered the importance of land, earnings uncertainty, political economy considerations, liquidity 
constraints, different options for funding Social Security, and human capital decisions. These studies include Hubbard and Judd (1987), Imrohoroglu, Imrohoroglu, and Joines (1995, 1999), Kotlikoff (1996), Huang, Imrohoroglu, and Sargent (1997), Huggett and Ventura (1998), Cooley and Soares (1999a, 1999b), De Nardi, Imrohoroglu, and Sargent (1999), Kotlikoff, Smetters and Walliser (1998a, 1998b, 1999, and 2002), Raffelhüschen (1989, 1993), Heckman, Lochner, and Taber (1998), Bohn (2001), Smetters and Walliser (2004), Nishiyama and Smetters (2004), and Fehr and Habermann (2005).

This model, like our previous ones, builds on Auerbach-Kotlikoff's (1987) overlapping generation (OLG) model. Auerbach and Kotlikoff also simulated demographic transitions, but their model assumed that all agents gave birth at a fixed age, died and bequeathed at a fixed age, and received inheritances at a fixed age. Kotlikoff, Smetters, and Walliser (2001) advanced the Auerbach-Kotlikoff model by incorporating age-specific fertility and inheritance, lifespan extension, intragenerational earnings heterogeneity, and additional fiscal institutions. Fehr, Jokisch, and Kotlikoff (2004a,b, 2005) included lifespan uncertainty as well as bequests arising from incomplete annuitization. They also introduced multiple regions with international capital mobility and immigration.

As in Kotlikoff, Smetters, and Walliser (2001), our model features monozygotic reproduction with agents in their child-bearing years giving birth each year to fractions of children. This means of finessing marriage and family formation permits us to incorporate changes through time in agespecific fertility rates and to closely line up our model's age-specific population shares to those forecast for the four regions.

We assume that agents care about their children's utility when they are young and, as a consequence, make consumption expenditures on behalf of their children (pay for their consumption), but only when the children are young. We also assume that agents die with realistic mortality probabilities starting at age 68. Agents fully appreciate the uncertainty of their longevities and maximize, at any point in time, their expected remaining lifetime utilities. The inclusion of lifespan uncertainty permits a realistic modelling of bequests and inheritances.

We generate bequests by assuming that agents fail to annuitize their assets in old age. Hence, 
when they die, they leave undesired bequests to their children. Since agents die at different ages and have children of different ages, their heirs also inherit at different ages. Agents who were born when their parents were young receive inheritances later in their life than do their younger siblings. Finally, uninsurable lifespan uncertainty leads agents to gradually reduce their consumption in old age.

Our model also includes capital adjustment costs. As is well known, these costs can drive temporary wedges between the marginal products of capital in different regions and lead the market values of capital assets to temporarily differ from their replacement costs. Thus inclusion of adjustment costs in the model generates what amounts to regional stock markets and permits us to explore how population aging affects world stock prices through time.

A final, but very important, feature of our framework is its intra-cohort disaggregation. As in Kotlikoff, Smetters and Walliser (2001), we consider three income classes within each generation each with its own earnings ability. Immigrants are also split into these income classes permitting us to simulate the arrival of immigrants with different stocks of human and physical capital.

The following sections present the general structure of our model. A more detailed description of the three-country model is provided in Fehr, et al. (2003).

\section{Demographics}

Each region is populated by households who live at most to age 90. Consequently, there are 91 generations with surviving members at any point in time. The individual life cycle of a representative agent is described in Figure 1. Between ages 0 and 20 our agents are children who earn no money and are supported by their parents. At age 21 our agents leave their parents and go to work. Between ages 23 and 45 our agents give birth to fractions of children at the beginning of each year, i.e. the first (fraction of) children are born when the agents are 23 and the last are born when they are age 45. An agent's first-born children (fractions of children) leave home when the parents are age 43, while the last-born leave when the agents are age 66. Our agents die between ages 68 and 90. The probability of death is 1 at age 91. Children always outlive their parents, meaning that parents always outlive grandparents. To see this note that if a parent reaches age 90 , his or her oldest children will be 67 . These are children who were born when the 
parent was age 23 .

In each year new immigrants in each skill and age group arrive with the same number and age distribution of children and the same level of assets as natives of the identical skill and age. Since the demographic structure has the same general form in all four regions, it suffices to discuss a representative region and omit region indices.

To specify the current and future demographic structure of each region we start with year$2000^{1}$ age-specific population $[\bar{N}(a, 2000)]$ and age-specific net-immigration $[\overline{N M}(a, 2000)]$ counts.

In constructing existing as well as future age-population counts, we have to link each initial cohort between the ages of 1 and 68 to those of their parents who are still alive. The reason is that children receive bequests from their parents, and the levels and timing of these inheritances depend on the ages of their parents. This linkage is achieved by applying past fertility rates to each cohort under age 69 in year 2000. If, for example, 15 percent of the parents of newborns in 1980 were 25 years old, then 15 percent of the 20-year-old's in year 2000 are assigned to parents age 45 .

In addition, each cohort is split into three income classes $k$. Specifically, we assume that 35 percent of each cohort belong to the lowest income class, 10 percent to the top income class, and the remaining 55 percent to the middle income class. We denote the population vector for year $\mathrm{t}$ as $N(a, t, s, k)$ where $a=1, \ldots, s=23, \ldots, 45, k=1,2,3$. The term $s$ references the age of the parent at the time of birth of agents age $a$ in 2000 .

To determine the evolution of the population in each region over time, we applied region-, age-, and year-specific mortality and fertility rates to the cohorts alive in year 2000 as well as to their children as they reach their ages of fertility and mortality. In the baseline path the exogenous current and future mortality and fertility rates follow the medium variant of the United Nations population projection (UNPD, 2003 for the U.S., EU and Japan; UNPD, 2005 for China).

According to this projection, mortality rates will decline in all three regions over time. Consider the Japanese, whose 2000 life expectancy equaled 81.6. According to official projections,

\footnotetext{
${ }^{1}$ Although the economic model starts in year 2004, we chose year 2000 as the initial year for the population projections due to data availability.
} 
Japan's life expectancy in 2050 will reach 88.1. The Japanese, who now have a 4.5 year higher life expectancy than Americans and a 3.0 higher life expectancy than EU citizens, will continue to maintain their longevity lead through time. Indeed, projected 2050 U.S. life expectancy doesn't even exceed current Japanese life expectancy! In China life expectancy is now a full 10 years lower than life expectancy in Japan. And this 10 year gap is projected to continue for the next half decade.

Table 1 shows our agent's life expectancies at birth in the baseline path, which is kept constant after year 2050. The respective numbers are higher than the actual values, since our model's agents don't die prior to age 68. However, the model's life expectancies conditional on reaching age 60 are close to those reported by the UNPD (2005).

Total fertility rates currently equal 2.1, 1.3, 1.6 and 1.5 in the U.S., Japan, China, and the EU, respectively. Nevertheless the United Nations expects fertility rates in all three regions to converge to 1.85 children by 2050. This path of fertility rates is also shown in Table 1 . In the baseline path, we assume annual net immigration of 1 million per year in the U.S., 450,000 in the EU, and 54,000 in Japan. Net immigration into China is negative. The number of net emigrants is fixed at its current value of 390,000 people per year. Given the population age structure in year 2000 as well as projected future fertility, mortality, and net immigration rates, we compute the population vector $N(a, t, s, k)$ for the years $t$ between 2001 and 2050. After year 2050, fertility rates are endogenously adjusted in order to achieve zero population growth and a stable population age structure. Since net immigration is positive in the U.S., the EU, and Japan, the populationstabilizing post-2050 fertility rates are below 2.0. Equivalently, the fertility rates in China are set above 2.0 after 2050 due to net emigration.

Table 1 also shows projected changes over time in total populations and population age structures. Due to high fertility and net immigration rates, the U.S. population is projected to increase from 275 million in 2000 to 442 million in 2100. In Europe, the population falls over the century from 375 to 340 million, and in Japan, the population falls from 126 million to 85 million. The Chinese population decreases by even more - from 1.3 billion to 1.2 billion.

As one would expect, the population share of those 65 and older increases in all four regions. 
There are, however, big differences in the aging process across the four regions. First, in the U.S. and China the absolute decrease of the shares of the young population through 2050 are almost the same as for the working age population. In contrast, the EU and Japan experience much larger absolute declines in the share of the population that is of working age. Second, the share of elderly increases to a much larger extent in Japan and China compared to the U.S. and the EU.

Table 1 indicates that our model's demographic machinery does a remarkably good job matching official projections for the four regions both with respect to the absolute number and age compositions of their respective populations. We now describe this machinery in more detail.

The total number of children of an agent age $a$ in income class $k$ in year $t$ is recorded by the following function

$$
K I D(a, t, k)=\sum_{j=u}^{m} \frac{N(j, t, a-j, k)}{\sum_{s=23}^{45} N(a, t, s, k)} \quad 23 \leq a \leq 65, k=1,2,3,
$$

where $u=\max (0 ; a-45)$ and $m=\min (20, a-23)$. Recall that agents younger than 23 have no children and those over 65 have only adult children, i.e. $K I D(a, t, k)=0$ for $0 \leq a \leq 22$ and $66 \leq a \leq 90$. Agents between these ages have children. Take, for example, a 30 year-old agent. Such an agent has children who were born in the years $(a-j)$ since she/he was 23. In year $t$, these children are between age $0 \leq j \leq 7$. The KID-function (1) sums the total number of kids of the respective parent-income class generation and divides it by the total number of parents of age $a$ in year $t$ who belong to income class $k$. This function takes into account that the family's age structure will change over time due to changing fertility. This approach permits the distribution of births by the ages of parents to change over time - an important improvement relative to the birthing process stipulated in Kotlikoff, Smetters and Walliser (2001).

\section{The Household Sector}

As previously mentioned, we do not distinguish between natives and immigrants once the immigrants have joined the native earnings- and age-specific cohorts. The model's preference structure is represented by a time-separable, nested, CES utility function. Remaining lifetime utility $U(j, t, s, k)$ of a generation of age $j$ at time $t$ whose parents were age $s$ at time of birth and 
who belongs to income class $k$ takes the form

$$
U(j, t, s, k)=V(j, t, s, k)+H(j, t, s, k)
$$

where $V(j, t, s, k)$ records the agent's utility from her/his own goods and leisure consumption and $H(j, t, s, k)$ denotes the agent's utility from the consumption of her/his children. The two sub-utility functions are defined as follows:

$$
\begin{aligned}
V(j, t, s, k) & =\frac{1}{1-\frac{1}{\gamma}} \sum_{a=j}^{90}\left(\frac{1}{1+\theta}\right)^{a-j} P(a, i)\left[c(a, i, s, k)^{1-\frac{1}{\rho}}+\alpha \ell(a, i, s, k)^{1-\frac{1}{\rho}}\right]^{\frac{1-\frac{1}{\gamma}}{1-\frac{1}{\rho}}} \\
H(j, t, s, k) & =\frac{1}{1-\frac{1}{\gamma}} \sum_{a=j}^{90}\left(\frac{1}{1+\theta}\right)^{a-j} P(a, i) K I D(a, i, k) c_{K}(a, i, s, k)^{1-\frac{1}{\gamma}},
\end{aligned}
$$

where $c(a, i, s, k)$ and $\ell(a, i, s, k)$ denote consumption and leisure, respectively, and $i$ is defined as $i=t+a-j$. The children's consumption of income class $k$ parents who are age $a$ in period $i$ and whose parents were age $s$ at the time of their birth is defined as $c_{K}(a, i, s, k)$. Note that the number of children is independent of the grandparent's age at the time of the birth of the parents.

Since lifespan is uncertain, the utility of consumption in future periods is weighted by the survival probability of reaching age $a$ in year $i$

$$
P(a, i)=\prod_{u=j}^{a}[1-d(u, u-a+i)],
$$

which is determined by multiplying the conditional survival probabilities from year $t$ (when the agent's age is $j$ ) up to year $i$. Note that $d(j, t)$ is the mortality probability of an agent age $j$ in year $t$. The parameters $\theta, \rho, \alpha$ and $\gamma$ represent the "pure" rate of time preference, the intratemporal elasticity of substitution between consumption and leisure at each age $a$, the leisure preference parameter, and the intertemporal elasticity of substitution between consumption and leisure in different years, respectively.

In maximizing utility, agents choose their demand for leisure subject to the constraint that leisure in each period not exceed 1, which is the time endowment. The determination of the shadow values of these leisure constraints, when these constraints are binding, is included as part of the maximization. To ensure that agents retire by a designated maximum retirement age, we set the net wage at that age and thereafter to zero. 
Given the asset endowment a $(j, t, s, k)$ of the agent in year $t$, maximization of $(2)$ is subject to a lifetime budget constraint defined by the sequence:

$$
\begin{array}{r}
\mathrm{a}(j+1, t+1, s, k)=[\mathrm{a}(j, t, s, k)+I(j, t, s, k)](1+r(t))+w(t) E(a, k)[h(a, t)-\ell(a, t, s, k)] \\
-T(j, t, s, k)-c(j, t, s, k)-K I D(j, t, k) c_{K}(j, t, s, k),
\end{array}
$$

where $r(t)$ is the pre-tax return on savings and $I(j, t, s, k)$ denotes the inheritance the agent receives in year $t$. When the parents die between age 68 and 90, their remaining assets are split between their children. Consequently, inheritances of agents who are age $j$ in year $t$ and whose parents were age $s$ at their birth are defined by:

$$
I(j, t, s, k)=\frac{d(j+s) \bar{A}(j+s, t, k)}{\sum_{u=23}^{45} N(j+s-u, t, u, k)} .
$$

The numerator defines the aggregate assets of income class $k$ parents who die in year $t$ at age $j+s$. The denominator defines these parents' total number of children who are between ages $j+s-45$ and $j+s-23$ in year $t$. The receipt of inheritances requires us to distinguish members of each cohort according to the ages of their parents at birth. The parents' ages at death determine when the children receive their inheritances. While the oldest children (born when their parents are age 23) receive their inheritances between ages 45 and 67, the youngest children (born when their parents are age 45) receive their inheritances earlier in life, between ages 23 and 45.

As in Altig et al. (2001) and Kotlikoff, Smetters and Walliser (2001), we assume that technical progress causes the time endowment $h(\cdot)$ of each successive generation to grow at the rate $\lambda$, i.e.

$$
h(a, i)=(1+\lambda) h(a, i-1) .
$$

The proposition here is not that time, per se, expands for successive generations, but rather that each successive generation is more effective in using time to either preform work or enjoy leisure. Treating technical change in this manner is essential to ensure that the economy achieves a long-run steady state. The assumption of labor-augmenting technical change would not, for example, be compatible with a long-run steady state given the nature of the model's preferences. And having the economy achieve a long-run steady state provides, in effect, the terminal conditions needed by our algorithm to solve for the model's equilibrium transition path. 
Gross labor income of the agent in year $t$ is derived as the product of her/his labor supply and her/his wage rate. The latter is the product of the gross wage rate $w(t)$ in period $t$ and the age- and class-specific earnings ability.

$$
\begin{aligned}
& E(a, k)=\xi(k) e^{4.47+0.033(a-20)-0.00067(a-20)^{2}}(1+\lambda)^{a-21} \quad \text { with } \\
& \quad \xi(1)=0.2, \xi(2)=1.0, \xi(3)=5.0
\end{aligned}
$$

The middle-income class profile is taken from Auerbach and Kotlikoff (1987). The shift parameters $\xi(k)$ are then applied to derive income class-specific profiles. Moreover, since technological change is an important determinant of secular growth over the life cycle, we multiply the age-specific longitudinal earnings ability profile by the term involving $\lambda$. Hence, the longitudinal age-wage profile is steeper the greater is the rate of technological change.

The net taxes $T(j, t, s, k)$ of an agent in year $t$ consist of consumption, capital income, and progressive wage taxes as well as social security contributions net of pension and disability benefits received. Due to our assumed ceiling on payroll tax contributions, pension, disability insurance, and health-care average and marginal payroll tax rates differ across agents. Each agent's pension benefits depend on her/his pre-retirement earnings history, while health care and disability transfers are provided on a per capita basis to all eligible age groups.

Given individual consumption, leisure, and asset levels of all agents, we can compute aggregate variables. For example, the aggregate value of assets $A(t+1)$ in period $t$ is computed from

$$
A(t+1)=\sum_{k=1}^{3} \sum_{a=21}^{90} \underbrace{\sum_{s=23}^{45} \mathrm{a}(a+1, t+1, s, k) N(a, t, s, k)}_{\bar{A}(a+1, t+1, k)}
$$

Since households die at the beginning of each period, we have to aggregate across all agents who lived in the previous period in order to compute $\bar{A}(a+1, t+1, k)$, which we need for the calculation of bequests, see (7). If we aggregate across agents who live in period $t+1$, i.e.,

$$
\mathcal{A}(t+1)=\sum_{k=1}^{3} \sum_{a=21}^{90} \sum_{s=23}^{45} \mathrm{a}(a, t+1, s, k) N(a, t+1, s, k)
$$

assets of the arriving immigrants of period $t+1$ are included. 
Finally, aggregate labor supply of agents in year $t, L(t)$, is computed from the individual labor supplies, i.e.

$$
L(t)=\sum_{k=1}^{3} \sum_{a=21}^{90} \sum_{s=23}^{45} E(a, k)[h(a, t)-\ell(a, t, s, k)] N(a, t, s, k) .
$$

\section{The Production Sector}

The economy is populated by a large number of identical firms, the total number of which is normalized to unity. Aggregate output (net of depreciation) is produced using Cobb-Douglas production technology, i.e.

$$
F(K(t), L(t))=\phi K(t)^{\varepsilon} L(t)^{1-\varepsilon}
$$

where $K(t)$ is aggregate capital in period $t, \varepsilon$ is capital's share in production, and $\phi$ is a technology parameter. Since we posit convex capital adjustment cost, the firms' marketable output in year $t, Y(t)$, is given by the difference between gross output and adjustment costs, i.e.

$$
Y(t)=F(K(t), L(t))-0.5 \psi \Delta K(t)^{2} / K(t)
$$

where $\Delta K(t)$ measures investment in year $t$. The term $\psi$ is the adjustment cost coefficient. Larger values of $\psi$ imply higher marginal costs of new capital goods for a given rate of investment. The installation technology is linear homogeneous and shows increasing marginal cost of investment (or, symmetrically, disinvestment): faster adjustment requires a greater than proportional rise in adjustment costs.

Corporate taxes, $T^{k}(t)$, are given by

$$
T^{k}(t)=\tau^{k}(t)[Y(t)-w(t) L(t)-\epsilon(t) \Delta K(t)]
$$

where $\tau^{k}(t)$ and $\epsilon(t)$ define the corporate tax rate and the immediate write-off share of investment expenditures, respectively. Since adjustment costs are fully, and investment expenditures are partly, deductible from the tax base, arbitrage between new and existing capital implies that the latter has a price per unit of

$$
q(t+1)=1-\epsilon(t) \tau^{k}(t)+\left[1-\tau^{k}(t)\right] \psi \Delta K(t) / K(t)
$$


Similarly, the arbitrage condition arising from profit maximization requires identical returns to financial and real investments:

$$
r(t) q(t)=\left[1-\tau^{k}(t)\right]\left\{F_{K(t)}+0.5 \psi(\Delta K(t) / K(t))^{2}\right\}+q(t+1)-q(t) .
$$

The left side gives the return on a financial investment of amount $q(t)$, while the return on one unit of real capital investment is the net return to capital (which includes the marginal product of capital $F_{K(t)}$ plus the reduction in marginal adjustment costs) and capital gains.

\section{The Government Sector}

The consolidated government issues new debt $\Delta B(t)$ and collects corporate taxes and nettaxes from households in order to finance general government expenditures $G(t)$ as well as interest payments on its debt:

$$
\Delta B(t)+T^{k}(t)+\sum_{k=1}^{3} \sum_{a=21}^{90} \sum_{s=23}^{45} T(a, t, s, k) N(a, t, s, k)=G(t)+r(t) B(t) .
$$

With respect to public debt, we assume that the government maintains an exogenously fixed ratio of debt to output. The progressivity of the wage tax system is modelled as in Auerbach and Kotlikoff (1987). Specifically, marginal wage tax rates rise linearly with the tax base.

$P Y(t)$ defines the aggregate payroll tax base, which differs from total labor earnings due to the ceiling on taxable wages. This ceiling is fixed at 250,200, 168, and 300 percent of average income in the U.S., EU, Japan, and China, respectively. Aggregate average social security payroll tax rates $\hat{\tau}^{p}, \hat{\tau}^{h}$ and $\hat{\tau}^{d}$ are computed each period from the relevant budget constraint for the program and region in question, i.e.

$$
\hat{\tau}^{p}(t) P Y(t)=P B(t) \quad \hat{\tau}^{h}(t) P Y(t)=H B(t) \quad \text { and } \quad \hat{\tau}^{d}(t) P Y(t)=D B(t),
$$

where $P B(t), H B(t)$ and $D B(t)$ are total outlays of the pension, health care, and disability systems, respectively. For China we assume that disability insurance is part of the state pension system. Hence, we do not calculate separate disability insurance payroll tax rates for this country.

Due to contribution ceilings, individual pension, disability and health insurance payroll tax rates can differ from the payroll tax rate. Above the contribution ceiling, marginal social security 
contributions are zero and average social security contributions fall with the agent's income. To accommodate this non-convexity of the budget constraint, we assume that the highest earnings class in each region pays pension and, in the EU, Japan and China, health insurance payroll taxes, up to the relevant ceilings, but faces no pension and no health care payroll taxes at the margin. The other earnings classes are assumed to face the full statutory tax rate on all earnings. The disability payroll taxes in the U.S., the EU and Japan are modelled in an equivalent manner. However, since there is no ceiling on U.S. Medicare taxes, all earnings groups are assumed to face the health insurance payroll tax at the margin.

If a $k$-income class agent, whose parents were $s$ years old at his birth, retires in year $z$ at the exogenously set retirement age $\bar{a}(z)$, her/his pension benefits $\operatorname{Pen}(a, i, s, k)$ in years $i \geq z$ when he is age $a \geq \bar{a}(z)$ depend linearly on her/his average earnings during his working time $\bar{W}(z, s, k)$ :

$$
\operatorname{Pen}(a, i, s, k)=\omega_{0}+\omega_{1} \times \bar{W}(z, s, k) .
$$

The region-specific parameters $\omega_{0}, \omega_{1}$ in the U.S., the EU and Japan were chosen in order to approximate replacement rates relative to individual lifetime earnings as reported in Whitehouse (2002). In China, we assumed a pension-replacement rate of 50 percent of average pre-retirement earnings. There is little reliable data to assess the accuracy of this replacement rate assumption. But the assumption seems reasonable given the Chinese government's recent decision to recognize the unfunded liabilities of state-owned enterprize.

General government expenditures $G(t)$ consist of government purchases of goods and services, including educational expenditures and health outlays. Over the transition, general government purchases of goods and services are held fixed as a percent of national income. Age-specific education and disability outlays are held fixed per capita over the transition with an adjustment for technological change. Age-specific health outlays are also held fixed per capita, but are assumed to grow at twice the rate of technological change during the first 25 years of the transition. Afterwards, the age-specific levels of these outlays grow at the same rate as technological change. Note that while the outlays of the health care systems are treated as government expenditures, disability benefits are modelled as direct transfers to the households. The government's budget (18) is balanced each year by adjusting the intercept in our linear equation determining the average 
wage tax rate.

\section{World Equilibrium}

Up to now we've described the model for the representative economy. The four regions of the model are, however, connected through the world capital market. A condition of this market is that the value of aggregate world assets equals the market value of the world-wide capital stock plus the value of all outstanding government bonds; i.e.,

$$
\sum_{x \in W} \mathcal{A}(t, x)=\sum_{x \in W}[q(t, x) K(t, x)+B(t, x)], \quad \text { with } \quad W=\{\mathrm{U} . \mathrm{S} ., \text { EU, Japan, China }\}
$$

\section{Solving the Model}

To simulate the model we need, of course, to specify preference, technology, and policy parameters. Table 2 reports these values, which, in the case of preference and technology parameters, are mostly taken from Kotlikoff, Smetters and Walliser (2001).

The multi-factor technology coefficient in the U.S. Cobb-Douglas function was set to generate a U.S. marginal product of labor of 1.0 in the initial year 2004. For the EU and Japan we simply adopted this technology level. For China the technology level was set to achieve a 2004 real wage equal to 15 percent of the U.S. level. During the transition we gradually adjust China's technology level such that it reaches the developed world level in 2050.

The time-preference rates in the four regions were set to match the model's 2004 ratios of private consumption to national income to the region-specific values reported in European Commission (2005). The U.S., EU, and Japanese time-preferences rates are held fixed through tim. But in line with our baseline assumption that the Chinese public will eventually adopt American spending habits, we gradually raise the time preference rate of successive Chinese cohorts so that the cohorts that reach adulthood (age 21) in 2030 and thereafter have the time-invariant U.S. time preference rate.

The model's debt levels in the four regions were chosen to accord with real government interest payments reported in European Commission (2005) for the year 2004. The maximum ages of retirement are taken from Bloendal and Scarpetta (1999) for the U.S. and the EU, from 
Whitehouse (2002) for Japan and from OECD (2002) for China. We set the consumption tax rate, personal capital income tax rate, corporate income tax rate, and expensing rate for the U.S., the EU, and Japan in line with the structure of indirect and direct tax revenues reported in European Commission (2005). We use OECD (2002) data to determine China's consumption tax rate, but assume China has no personal capital income or corporate income taxes. It may well be that such taxes exist in China, but we have no reliable information to understand their magnitudes.

Our wage tax systems are assumed to be progressive, with the parameters of these tax systems in each region set so as to generate what seem to be realistic average and marginal tax rates, which are reported below.

In calibrating health expenditures in our model, we apply the Japanese age-specific government healthcare expenditure profile for Japan as well as China. In the case of the EU, we use the German profile. For the U.S., the Medicare program applies only to households 65 and older. We assume uniform Medicare expenditures by age. We make the same uniform age-distribution assumption with respect to the disability insurance systems in the U.S., the EU, and Japan, which we assume applies only to those older than 20 and younger than 65 .

In the case of the U.S., EU, and Japan, total social insurance outlays for pensions, disability, and health, measured as a share of national income, are set to accord with the values of these totals reported in European Commission (2005). But we determined the composition of these expenditures as between the three types of benefits using data reported in Docteur and Oxley (2003), European Commission (2003), and OECD (2001) and invoking the assumption for the EU and Japan that their ratios of disability expenditures to pension expenditures is the same as prevails in the U.S. Note that our baseline path assumes a gradual 20 percent cut in Japanese pension replacement rates through 2017, which was recently legislated by the Japanese government. For China our division of social insurance outlays is restricted to pensions plus disability payments, on the one hand, and health expenditures, on the other. Calibration here is based on OECD (2002).

We use the German age-specific education profile for all regions in the model and rescale it to get realistic education outlays in year 2004 in each region (see below). In addition to these 
parameter values, our model requires an initial distribution of assets by age and income class for each region. These profiles are region-specific. ${ }^{2}$

To run our model as an open world economy, we also need to specify total world assets and how these assets are distributed across regions. The model's level of total world assets was set to generate a capital-output ratio of 3.0 in our model in the absence of China. Our additional assumption that per capita wealth in China equals 10 percent of per capital wealth in the developed countries sufficed to pin down the capital-output ratio in the four-region model, namely 2.3.

In our simulations with adjustment costs, we also need to specify, for 2004, the base year, the shares of wealth in each country owned by citizens of each region. The reason is that the endogenous determination of capital prices in each region will differentially affect wealth holdings of each region's nationals depending on where they hold their wealth. The data needed to determine the region-specific allocation of each region's wealth holdings are not available. Consequently, we make the following, admittedly crude, assumption. We assume that each U.S., EU, Japanese, and Chinese nationals own 70 percent of the capital installed in their region and that the remaining 30 percent is owned equally by foreigners from the other three regions. In the case of the U.S., for example, we assume that the Japanese, European Unioners, and Chinese each own 10 percent of the U.S. capital stock, where these holdings include government claims.

The initial (year 2004) world capital stock, the allocation of this capital stock across regions, the regional ratios of government debt to national income, and the international, intergenerational, and intragenerational distributions of assets constitute the initial conditions needed to solve for the perfect foresight general equilibrium transition path of the economy. The algorithm we use to solve the model employs Gauss-Seidel iteration.

Specifically, our algorithm starts with initial guesses for capital stocks and labor supplies in each region for the post-2004 years of the transition. Next we compute from equation (16) the path of the q's - the region-specific market prices of capital. The path for the world interest

\footnotetext{
${ }^{2}$ The profile of Japanese average net wealth by age was provided by Charles Horioka, while the European agespecific average wealth profiles was adjusted from German data provided by Reinhold Schnabel. We calculated a U.S. age-wealth profile using the 1998 Survey of Consumer Finances. For China, we adopted the Japanese age-net wealth profile.
} 
rate is derived from the arbitrage condition (17) for the U.S. Next, region-specific wage rates are computed for each year by setting them equal to their respective marginal products of labor.

The initial region-specific capital values, our working value of q in 2004, and 2004 initial region-specific debt levels suffices to determine total worldwide wealth in 2004 using the world capital market equilibrium condition (21). These aggregate values are then distributed to the agents of each region based on the initial 2004 region-specific wealth shares and region-specific age-asset profiles.

Given these initial individual asset holdings, our initial guesses of tax rates/tax function parameters, as well as the derived time paths of wage and interest rates, we calculate household consumption, saving, and labor supply decisions. The first-order conditions and lifetime budget constraints determining these decisions are fairly complex and certainly do not omit of closed form solutions. Part of this complexity arises because of the progressive nature of our assumed wage tax structures, which means that marginal tax rates are themselves endogenous and need to be determined jointly with life-cycle consumption, saving, and labor supply decisions. This is done using Gauss-Seidel iteration. We refer to this as "inter-loop" convergence. As indicated momentarily, we also use Gauss-Seidel iteration to determine the time path of the economy's macroeconomic variables. We refer to this iteration on macro variables as "outer-loop" convergence.

The next step in our overall solution algorithm uses the annual revenues and Social Security benefit payments implied by these household decisions to update annual tax rates/tax parameters. We also update the model's region-specific time paths of government debt. These updates are based on equations (18) and (19).

Aggregating individual labor supplies in each year provides new time paths of aggregate region-specific labor supplies. Determining new time paths of capital stocks in each region is a bit more involved. First, we use year-2004 wealth holdings plus agent-specific saving decisions to determine agent-specific asset holdings in each year during the transition. Second, we aggregate agent-specific assets at each date to determine a time-path of aggregate world-wide asset holdings. Third, use (17) to substitute out for $\Delta K(t) / K$ - the percentage change in capital - in (16). Finally, we equate the interest rates in Japan, the EU, and China to that in the U.S. using the modified 
versions of (16). Given our working values of the $q$ 's, this provides us with three equations in a given year to solve for the four region-specific capital stocks. The fourth equation comes from the worldwide capital market condition, which, given our working values of $q$ 's and debt, provides another equation in the four unknown region-specific capital stocks.

The new values for the aggregate supplies of capital and labor in each region in each year are then weighted with the initial guesses of these variables to form new guesses of their time paths. The algorithm then iterates until the region-specific time paths of capital stocks and labor supplies converge to a fixed point.

We give our economy 300 years to reach to a steady state. In fact, our model reaches a steady state to many decimal places decades prior to year 300. It also converges very tightly around the equilibrium transition path. However, when we include capital adjustment costs finding the equilibrium transition path is very time consuming even on today's most powerful desktop PCs. Doing so requires finding the path with no such costs, which can be done relatively quickly, and then using the region-specific capital and labor supply equilibrium paths from that simulation as the initial guesses for a run with very small adjustment costs. We then use the results of the small adjustment costs simulation as initial guesses for a simulation with somewhat higher adjustment costs and proceed in this manner until we've solved the model with our desired level of adjustment costs. Given the time required for these calculations, we assumed no adjustment costs in all but one simulation presented below. The simulation with adjustment costs is of the base case transition. The results indicate that inclusion of reasonable adjustment costs make little difference to the results.

\section{Initial Equilibrium and the World Economy's Baseline Transition Path}

Table 3 reports key macroeconomic variables in 2004 in the four regions. Note that there is a fairly close accordance between actual and computed values of private consumption and government purchases measured as a share of national income. The one exception is EU government purchases. The official data seem too low given the reported ratio of tax revenues to national income. In our calibration, we chose to benchmark government purchases based on the ratio of tax revenues to national income. 
The reported ratios of educational expenditure to national income are very close to actual levels ${ }^{3}$. In the case of pension, health, and disability, expenditures, we closely match the shares of national income received in the form of social contributions in the U.S., the EU and Japan as reported in European Commission (2005). In China, the level of health expenditures measured as a share of national income was set in accord with WHO $(2004,136)$. The resulting social security payroll tax rates come close to observed levels. Concerning the overall structure of tax revenues, the assumed tax rates on capital income, corporate income, and consumption as well as the expensing fractions (see Table 2) yield a realistic pattern ${ }^{4}$.

The baseline simulation ignores adjustment costs. Hence, capital prices do not change during the transition. However, due to the differences in the expensing fractions for the corporate tax, capital prices deviate from one in the EU and Japan. Thus the capital price is 0.964 in the EU and 0.936 in Japan throughout the transition, while it is 1.000 in the U.S. and China. Finally, the model's year-2004 capital-output ratios seem reasonable not only relative to U.S. Commerce Department figures, but also in terms of the year-2004 marginal product of capital, which equals 9.8 percent.

Next we turn to the simulation results for the baseline transition. The transition paths for the four regions are reported in the upper panels of Tables 4 to 7 for the U.S., the EU, Japan, and China. Note that region-specific ratios of national income, the capital stock, the supply of labor, and the pre-tax wage rate are all expressed relative to the U.S. values in year 2004.

Although the four economies are aging, the baseline path shows a steady increase in effective labor supply in the U.S., the EU and Japan. This may seem surprising especially for Japan and the EU where the population and work force decline over time (see Table 1). The explanation lies in our assumption that each successive cohort has a higher effective time endowment, which admits greater effective labor supply by each successive cohort. Thus, the future decrease in the actual labor force is offset in the EU, Japan, and China and the growth in the actual number of workers in the U.S. is augmented. However, effective labor supply grows at much different rates in the regions. In Japan it increases over the century by 41 percent. In the EU it more than doubles

\footnotetext{
${ }^{3}$ See OECD (2003a, 178; 2003b, 71, 77).

${ }^{4}$ Actual values are calculated from European Commission (2005) and OECD (2003c).
} 
over the same period. And in the U.S. it increases over the century by a factor of almost four.

The evolution of effective labor supply in China is particularly interesting. During the next two decades effective labor supply increases, then it declines until mid century when it begins to increase again. This complex pattern reflects major changes in substitution and income effects over the transition, the demographic changes themselves, as well as the ongoing technological change. By the end of the century, China's effective labor supply is larger, but only 18 percent larger, than it is today.

Due to the dramatic aging of populations,social security tax rates increase through 2050 by 5.5 percentage points in the U.S., by 12.8 percentage points in the EU, by 13.8 percentage points in Japan, and by 7.8 percentage points in China. Over the century the respective increases are 11.4 percentage points in the U.S. and the EU, 10.7 percentage points in Japan and 16.6 percentage points in China. These changes constitute very major percentage payroll tax hikes given the base-year values. In the U.S. and China, for example, the model is predicting more than a 100 percent rise in payroll tax rates.

Despite the rising payroll tax burden, capital stocks rise dramatically in all regions over the course of the century. The capital stock increases by a factor of 4.7 in the U.S., by a factor of 2.5 in the EU, by a factor of 1.7 in Japan and by a factor of 9.6 in China. In China this development is due to high investment rates associated with high private saving and the assumed rapid catch-up in the country's level of technology. The other regions also benefit from the economic boom in China. As the development of the current accounts suggests, initially capital mainly flows from the three developed regions to China. However, in subsequent decades the asset holdings of the U.S., the EU, and Japan in China decline and capital starts to flow from China to all three of these regions. After 2050, this is reversed again so that capital flows from the U.S., EU, and Japan back to China. This reversal is expected; it reflects the repatriation of Chinese foreign capital earnings back to China.

The differences across the four regions in the growth of effective labor supply and capital stock and, in the case of China, in the evolution of the multifactor productivity coefficient materially affects overall economic growth. In the U.S. output grows by a factor of 4.1 over the next 100 
years. It grows by a factor of 2.2 in the EU, 1.4 in Japan and 8.5 in China. The larger increase in capital compared to labor supply leads to an increase in the pre-tax wage rate in the developed economies of almost 16 percent through the middle of the century. In China wages rise by more than 700 percent thanks, primarily, to the gradual increase in China's technology level. After 2050, however, growth in labor supply exceeds growth in capital stocks in all regions so that the wage rate starts to decline. At the end of the century real wages per unit of human capital in the developed economies are still above 2004 levels, but only 4 percent higher.

As one would expect, the world-wide capital deepening in the first half of the century and capital-shallowing in the second half has a major impact on the world interest rate. Between 2004 and 2030 the world interest rate declines by 370 basis points - from .098 to .061 . This is followed by an increase to a 2100 level of .087 percent. Wage tax rates follow a similar pattern - declining in the first half of the century and rising in the second half.

This interesting pattern in the evolution of factor prices reflects China's ongoing rapid growth and its assumed gradual change in saving behavior. During the first half of the century, China makes a major contribution to world-wide capital formation. In the second half of the century, more and more of its cohorts have adopted U.S. preferences with respect to spending and the Chinese saving engine starts to sputter and fail.

To understand better the role of China in worldwide capital formation, let's consider what would happen were the developed world forced to evolve without the ability to import capital from China.

\section{The World Economy's Baseline Transition Path Excluding China}

Table 8 reports baseline transition paths for the developed economies if we calibrate the model as above, but simply exclude China. Doing so has dramatic effects. Capital stocks in all three regions in the initial years of the transition are much higher compared to the four-country case since more capital now remains in the developed world. For example, in 2010 the capital stock index in the U.S. is 1.60 compared with 1.02 in the 4-country simulation (see Table 4). In both simulations, the capital stock is measured relative to the U.S. value in 2004 in the 4-country simulation. 
Interestingly, even though the developed world has more capital to work with initially, real wages are actually lower in 2010 than in the transition with China. The reason is that labor supply is initially also much higher in the developed world in the no-China simulation. Presumably this reflects the income effect of having lower real wages in the medium term when China is no longer serving as the developed world's saving machine.

With China out of the picture, the developed regions' capital stocks increase much less rapidly over time. This puts a significant damper on output growth. During the first half of the century, capital growth is somewhat larger than labor supply growth. Thus wage rates increase by approximately 2 percent and the world interest rate decreases by about 30 basis points. In the second half of the century, however, all three regions experience a capital shortage due to the high tax burden. As a consequence, wage rates decline. Indeed, the 2100 wage per unit of human capital is 4 percent below its 2004 level, and the interest rate is 100 basis points above its base year value. The lower level of real wages in the no-China transition leads to higher average wage and payroll tax rates, both of which limit capital accumulation.

The current accounts show that capital flows primarily to the U.S. during the coming decades due to its younger population and higher population growth rate. After 2050, capital flows to the EU and increasingly to Japan as the Europeans and Japanese repatriate their U.S.-earned income.

As indicated in the introduction, the no-China developed world transition path shows a relatively modest capital shortage compared to our previous findings reported in Fehr, Jokisch and Kotlikoff (2004a,b; 2005). The main reason, again, is that we are now calibrating the model to include government investment. In addition, we've switched to using European Commission (2005) data for our measures of social contributions received. This lowers, somewhat, initial payroll tax rates as well as subsequent payroll tax hikes.

\section{Adjustment Costs}

Table 9 repeats the base-case simulation, but includes capital adjustment costs. A comparison of this table with the first panels in Tables 4 through 7 shows that adjustment costs make very little difference to the four-region dynamic equilibrium. The initial levels and times paths of regional stock prices per unit of physical capital (the ratio of market value to replacement cost) 
are, however, interesting.

In 2004, EU stock prices are 5.1 percent lower than US stock prices. Japanese stock prices are 12.6 percent lower, and Chinese stock prices are 16.1 percent higher. The model predicts increases in stock values in all four regions for the next 10 to 20 years, depending on the region, followed by a long term decline in stock values. The U.S. stock market value is 1.000 in 2004, hits 1.062 in 2020, and falls to .917 in 2100. The EU's 2004 stock market value is .949. It's .979 in 2020 and then gradually falls to .882 in 2100. Japan's 2004 stock market value is .874. In 2020 it's .938, but then falls to .851 by Century's end. And China's stock market value starts at 1.161 , reaches 1.196 in 2020 and declines to .914 in 2100.

\section{Examining China's Saving and Absorption of Technology}

This section returns to the four region model without adjustment costs and examines the importance of our assumptions about the evolution of Chinese saving behavior and the rate at which China absorbs developed-world technology. Specifically, we first consider keeping the time preference rate of successive Chinese cohorts at same the level calibrated for all Chinese cohorts for 2004 in the base case transition. Next we assume the technology coefficient in the Chinese Cobb-Douglas production function rises only to half, rather than 100 percent, of the U.S. level by 2050 and remains at that value thereafter.

\section{Constant Time Preference Rate in China}

The second simulation reported in Tables 4 through 7 from permanently maintains the Chinese time preference rate at its year-2004 level. Doing so has dramatic consequences. In particular, the 2100 world stock of capital is 5.9 times higher than in the base case! China not only becomes the world's saver. It also becomes the world's investor, sending huge flows of capital to the developed world over the course of the Century. By 2100, the capital stocks in the U.S., the EU, and Japan are 5.6, 5.6, and 5.8 times their initial values, respectively.

This huge impetus to capital formation has a major impact on economic growth in all four regions, leaving world output roughly 50 percent higher in 2100 than it would otherwise have been. This is true notwithstanding a basically unchanged supply of labor in the four regions. The 
rough constancy of labor supply reflects competing income and substitution effects arising from roughly 55 percent higher long-run (year 2100) levels of the real wage per unit of human capital. The long-run capital glut also leads to a very major decline in the world real interest rates - from 9.8 percent in 2004 to 2.3 percent in 2100 .

The long-run rise in real wages has a major effect on long-run payroll tax rates, although it does very little to payroll tax rates over the next three decades. Year-2100 payroll tax rates are now 16.4 percent instead of 23.0 percent in the U.S., 26.1 percent instead of 36.7 percent in the EU, 22.7 percent instead of 32.8 percent in Japan, and 26.0 percent instead of 27.7 percent in China. Higher output growth immediately translates into increased government expenditures. This explains the higher wage tax rates in the medium and long run.

\section{Slower Technology Growth in China}

Our next simulation, reported in the third panels of tables 4 through 7 , assumes that the multi-factor technology coefficient in the Chinese production function rises by 2050 to only 50 , rather than 100 percent of the U.S. level and remains fixed at half the U.S. level thereafter. As a comparison with the base case shows, slower Chinese technological growth means much lower capital demand, output, and real wage levels in China. Indeed, in 2100 the Chinese capital stock and output levels are just over half of their base-case values. And the Chinese real wage is only 39 percent of what it would otherwise have been.

In contrast to what happens to China's capital stock, China's labor supply is significantly higher along the entire transition path. This reflects the income effects (relative to the base case) experienced by the Chinese in receiving lower real wages as well as smaller inheritances. These income effects matter to labor supply from the get go. Indeed, the immediate increase in labor supply explains why Chinese output and capital stock levels are initially higher than they are in the base case.

The rise in China's labor supply doesn't suffice to offset the lower path of wages with respect to determining the Chinese payroll tax base. Consequently, social security payroll tax rates are markedly higher during this transition. 
The most interesting thing about this simulation of slower Chinese technological progress is what happens to the economies of the developed world. The answer, surprisingly, is very little. Although China saves much less than in the base case, it also demands significantly less capital. Consequently, the U.S., the EU, and Japan end up with essentially the same capital stocks, wage rates, and tax rates over time that they enjoy in the base case.

The welfare effects of this simulation are given in Table 9 . The numbers show the change in welfare measured as an equivalent variation and expressed as a percentage of remaining lifetime resources for cohorts born between 1920 and 2030. As expected from the macroeconomic development, middle-aged and future cohorts in China experience large welfare losses due to reduced wages and increased payroll tax rates during their lifetimes. The welfare changes for developed world cohorts are, in contrast, quite small.

\section{Population Policies}

In this section we analyze three different population scenarios. The first scenario keeps fertility rates fixed at their initial levels. The second scenario considers increases in life expectancy relative to the base case. The third scenario doubles rates of immigration in all four regions. ${ }^{5}$

\section{Fixed Fertility Rates in All Regions}

The fourth panels in Tables 4 through 7 show the impacts of keeping the initial fertility rate of 2.11 births per woman in the U.S., 1.46 births in the EU, 1.28 births in Japan and 1.62 births in China fixed through $2050 .^{6}$

The higher short-term U.S. fertility rate increases that country's total population as well as its effective labor supply. The latter variable is first affected in 2026 when the first cohort generated by the higher birth rate enters the labor force. Effective labor supply and national income in 2100 are raised by 17 percent relative to the baseline simulation. Due to the younger population age-structure and the increased labor supply, social security contribution rates in the

\footnotetext{
${ }^{5}$ A more extensive analysis of how different population policies affect the future fiscal and economic development in the developed world is presented in Fehr, Jokisch and Kotlikoff (2004a, b).

${ }^{6}$ After 2050 fertility rates gradually adjust again in order to achieve a zero long-run population growth rate.
} 
U.S. decrease. In 2100 the social security payroll tax is 20.9 percent, compared to 23 percent in

the base case. However, the average wage tax rate rises. Compared with the base case results, the average wage tax rate is 1.1 percentage points higher in 2100. This reflects the need to finance additional government expenditures associated with the population increase. The capital stock keeps pretty close track with the higher time path of labor supply. In 2100 the capital stock is 16 percent higher relative to the base case.

In the case of the EU, Japan, and China, holding fertility rates fixed at their 2004 values for the next 45 years leads to smaller work forces and populations. In the EU labor supply and national income in 2100 are 23 percent below their baseline values. These are big differences. In China, effective labor supply and national income in 2100 are both 17 percent lower. And in Japan, the maintenance of current fertility patterns through 2050 reduces effective labor supply at the end of the century by 33 percent and national income by 32 percent. Indeed, the absolute size of the Japanese economy, as measured by national income, is smaller in 2100 than in 2004 notwithstanding almost 100 years of technological progress!

Lower fertility rates raise dependency ratios in the three developed regions. This necessitates larger increases in social security tax rates. On the other hand, average wage tax rates are slightly reduced during the transition since government expenditures on education decrease with the reduction in the number of young people and general government expenditures decrease with the reduction in population growth. The higher payroll taxes in China, Japan, and the EU lead households to save less and export more capital to the U.S. Thus, capital stocks in the three regions decline during the second half of the century. Finally, since capital-labor ratios are little affected in the four regions, wage rates and the world interest rate remain almost the same as in the baseline path.

\section{Higher Life Expectancies in All Regions}

Now we consider a simultaneous rise in longevity in all regions. To be precise, we gradually raise life expectancy in each region through 2050 by approximately 3 years, i.e. life expectancy in 2050 is 86.8 years in the U.S., 87.6 years in the EU, 91 years in Japan, and 83.3 years in China. These values for the developed regions find support in the projections of Tuljapurkar, et. al. 
(2000). Simulation results for this scenario are reported in the fifth panels of Tables 4 through 7 .

Greater longevity leads to more saving for retirement as well as more labor supply to help generate this saving. Consequently, the labor supply and the capital stock increase in all four regions compared to the base case. The broadening of the tax base implies a slight decline in wage tax rates in the medium and long run. However, at the same time, higher life expectancy leads to a rise in dependency ratios. Hence, the year-2100 social security contribution rates are increased by 2.4 percentage points in the U.S., 2.3 percentage points in the EU, 2.2 percentage points in Japan and 4.1 percentage points in China. Since the increase in capital exceeds the increase in labor, wage rates rise slightly during the transition. Consequently, the values of the world interest rate are lower than in the baseline path.

\section{Doubling of Immigration in All Regions}

The sixth panels in Tables 4 through 7 show the impacts of immediately and permanently doubling immigration in all four regions. This means, for example, that in 20042 million immigrants enter the U.S., 900,000 enter the EU, 108,000 enter Japan, and 780,000 exit China.

As is clear from the figures for effective labor supply, doubling immigration makes a material difference to the long-run supply of labor in all four regions. Take the developed regions. Relative to the baseline simulation, this policy raises effective labor supply in 2100 by 31 percent in the U.S., by 21 percent in the EU, and by 10 percent in Japan. The remarkable thing is how long it takes for immigration to alter effective labor supplies. In the U.S., for example, the effective supply of labor is only 11 percent larger in 2030 despite a doubling of immigration starting in 2004. The comparable figures for the EU and Japan are 6 percent and 2 percent.

Given that the developed world's severe fiscal problems associated with aging will begin to appear well before 2030, it would seem that even a doubling of immigration is "too little too late". This, indeed, is what the other figures in the second panel of results show. Relative to the baseline simulation, doubling immigration makes little difference to any of the three countries in terms of their macroeconomic variables.

Take the U.S. In 2030 the payroll tax rate is 15.3 percent with a doubling of immigration 
- not much lower than the 16.4 percent rate without the extra immigrants. In 2100 the payroll tax rate is 22.4 percent, compared with 23.0 percent under base-case immigration policy. Factor prices are also essentially unchanged by a doubling of immigration. In 2030, the pre-tax wage is 1.17 in both simulations. And in 2100, the pre-tax wage is 1.05 compared to 1.04 in the base case. The explanation here is that while the long-run U.S. labor supply rises by 31 percent, the long-run capital stock rises by 33 percent, leaving the long-run capital-labor ratio essentially unchanged.

If the long-run real wage in the U.S. stays fixed, but labor supply rises by 31 percent, why doesn't the payroll tax rate and, for that matter, the average wage tax rate fall by 31 percent in light of the 31 percent larger long-run supply of effective labor? The answer is that the model provides new immigrants with public goods and social insurance benefits on the same basis as existing natives. And doubling the number of immigrants on an across-the-board basis ends up costing the U.S. government almost as much in additional expenditures as the U.S. government earns in additional revenues. As tables 5 and 6 indicate, the same can be said of the EU and Japan.

Of course, the opposite happens in China. Higher emigration reduces China's long-run labor supply by 5 percent and long-run capital stock by 3 percent. More emigrants means a reduction in the taxable wage base and thus an increase in payroll tax rates. However, as the results indicate, the changes in payroll tax rates are quite small.

Table 10 reports the welfare effects of doubling immigration. Almost all cohorts in the developed regions experience welfare gains, albeit mostly very small ones. For initially younger and future generations these gains stem from the reduction in payroll taxes. The gains are smaller for members of the high-skilled class because the ceiling on key payroll taxes limits the benefits they can experience from cuts in these taxes. Welfare gains are generally higher in the U.S. and the EU. This is particularly true of younger and future cohorts. Indeed, for the low-skilled cohort born in 2030, the welfare gain is 2.07 percent in the EU and 1.35 percent in the U.S., but only 1.03 percent in Japan. Unlike the gains of initial older generations, these gains are substantial. They appear to reflect the reduction in excess burden arising from even the modest reductions in marginal tax rates arising from the immigration reform. 
Initially middle-aged people in China experience small welfare gains which are mainly due to small reductions in the average wage tax. In contrast, younger and future cohorts experience welfare losses. Of course, the reasons are the higher payroll tax rates throughout the transition. As one would expect from the macroeconomic outcomes, welfare effects in China are much smaller than in the developed regions.

\section{Social Security Policies}

This section considers different social insurance policy scenarios. The first is a larger increase in health expenditures than that assumed in the base case. The second and third scenarios analyze the consequences of different financing methods for the social security systems. The fourth scenario considers cuts in state pension systems. The final scenario is a privatization of public pension systems.

\section{Increased Health Expenditures}

In this simulation, health expenditures increase by 3 percent during the first 25 years of the transition instead of the 2 percent rate assumed in the base case. The simulation results are shown in the seventh panels of Tables 4 through 7 .

Of course, higher health expenditures increase social security contributions. The additional increase in payroll taxes depend on the relative sizes of overall health expenditures and populations in each region. Thus in 2030, payroll tax rates are 1.3 percentage points in the U.S., 3.2 percentage points in the EU, and 3.5 percentage points in Japan and China above their baseline values. In year 2100 the difference is 1.8 percentage points in the U.S., 3.2 percentage points in the EU, 3.7 percentage points in Japan, and 0.8 percentage points in China.

The higher payroll tax burden leads to lower net wages. Consequently, medium-term and long-run capital stocks are below their respective base-case values. The lower capital formation is partly offset by higher capital inflows into the three developed regions from China during the first decades of the century. This explains the slightly increased output growth during this period. In the long run, output in the U.S. and China is lower compared to the base case and higher in the EU and Japan. This is due to the adjustment in effective labor supply in order to offset the 
income losses. Higher output growth during the first decades and lower wages in the second half of the century lead to an additional increase in wage tax rates.

The welfare effects of this simulation as reported in Table 11 confirm our macroeconomic findings. Apart from small welfare gains for initially older generations in the EU and Japan, all cohorts already alive in the initial year and all future cohorts experience welfare losses from increased health expenditures. The explanation is the higher payroll and wage tax rates. Since the additional tax burden increases with time, welfare losses rise with the birth year of the observed generations. Note also the differences in welfare losses between the four regions. Generations in the EU and Japan are hurt much more than people in the U.S. and China. This indicates the bigger size in health expenditures in the former two regions and thus the larger rise in tax rates.

\section{Financing Social Security Benefits at the Margin with General Tax Revenues}

Next we consider a scenario where payroll tax rates are fixed at their year-2004 value throughout the transition. The budgets of the social security systems are then financed by general tax revenues. The results are reported in the eighth panels of Tables 4 through 7 .

Balancing the future budgets of the social security systems by general tax revenues increases the wage tax rate in all four regions. In year 2100, the average wage tax rate is now 17.8 percent in the U.S. instead of 6.8 percent in the base case. In the EU it is 17.8 percent instead of 7.4 percent, in Japan 12.0 percent instead of 2.7 percent, and in China 17.6 percent instead of 1.9 percent. Note that the wage tax rates do not increase as much as the payroll tax rates would otherwise have risen because there is no ceiling on wages subject to taxation. This differentially reduces the welfare of high-earnings agents. It also reduces their ability to save and their desire to work. Thus capital stocks, labor supply and national income are lower than in the base case. The course of current accounts, wage rates, and interest rates are, however, little changed.

Table 13 records the welfare effects of this policy. Agents in the low- and middle income classes experience welfare gains since they now face a lower tax burden. Note also the differences in welfare effects between the developed regions, which stem from the different extents of population aging in the three regions. At first glance it might be surprising that initially middle-aged and younger cohorts in the low- and middle-income classes in China experience small welfare losses 
and those in the high-income class enjoy welfare gains. The reason is that payroll taxes in China decline in the base-case transition during the first few decades. Keeping payroll tax rates fixed at the year-2004 level translates into lower average wage tax rates during these decades than would otherwise be the case. This, of course, hurts people in the low- and middle-income class, while those in the high-income class gain.

\section{Financing Social Security Benefits With Government Debt}

This scenario examines the consequences of financing social security benefits through 2029 with government debt. To be precise, we keep payroll tax rates in each region fixed at their year2004 values through 2029. We also fix the intercept and the progressive terms of our wage tax rate formula at their 2004 values. The government's general budget and the budgets of the social security systems are then balanced with government debt. Starting in year 2030, payroll tax rates and the intercept of the payroll tax rate formula endogenously adjust to balance social security systems and government general budgets, respectively. In the years 2030 and thereafter we keep government debt fixed as a share of national income. The ninth panels in Tables 4 through 7 report results.

In the U.S. debt increases from 33.3 percent of national income in 2004 to 73.8 percent in 2100, in the EU from 38.9 percent in 2004 to 134.6 percent in 2100 and in Japan from 41.4 percent in 2004 to 249.5 percent in 2100. In China, payroll tax and wage tax rates decline, with some minor exceptions, in each year during the first few decades of the base-case transition. Consequently, holding these tax rates fixed through 2030 in China means running a surplus. Indeed, in 2100 government debt in China is negative 38.8 percent of national income, rather than positive 10 percent - its base-case year 2100 value.

Higher debt ultimately implies higher average tax rates in order to finance higher interest payments. In 2100, average wage tax rates are 11.8 percent in the U.S., 21.9 percent in the EU, and 30.5 percent in Japan. The corresponding 2100 base-case average wage tax rates are 6.8 percent in the U.S., 7.4 percent in the EU, and 2.7 percent in Japan.

These are, obviously, huge increases. Of course, one would expect that capital formation, labor supply and output growth to be greatly reduced by this policy. But this doesn't happen 
thanks to China's surplus.

Next consider the welfare effects of this policy shown in Table 14. Initial middle-aged and younger generations in the U.S., the EU and Japan gain from this policy reform. This reflects, of course, the fact that they enjoy constant rather than rising tax rates through 2030 . The gains are largest in Japan since in the baseline path the increase in social security contributions is the largest. Future cohorts in the developed regions experience remarkably large welfare losses. These stem from the large increase in wage taxes to finance the higher government debt. Take, as an example, members of the 2030 Japanese birth cohort. They experience a 20.25 percent welfare loss. These show the dramatic increase in excess burdens due to the adjustment in the wage taxes. The opposite is observed in China. Here middle-aged people lose from the reform since they now face higher payroll tax burdens. Future cohorts, however, experience welfare gains from the lower and even negative wage taxes.

\section{Cutting Pension-Benefit Replacement Rates}

As mentioned, our baseline path includes the legislated cut of the pension replacement rates in Japan of 20 percent that is being phased in between now and 2017. We now assume the same cut in all other regions over the same period. The simulation results are reported in the tenth panels of Tables 4 through 7 . In 2100, social security contribution rates are reduced by 3.6 percentage points in the U.S., by 4.7 percentage points in the EU, and by 4.6 percentage points in China compared to the respective baseline values. As one would expect, this policy increases capital formation in the three regions. Thus the long-run capital stock is increased by 11.6 percent in the U.S., by 10.3 percent in the EU and by 11.2 percent in China relative to the base case. At the same time, labor supply is slightly reduced, and output growth increases. The higher capital-labor ratios lead to higher wages and lower interest rates during the transition. Due to higher wage income, the average wage tax rates in the three regions are lower than in the baseline path.

The pension reform in the U.S., the EU and China also affects the Japanese economy in the future. Higher capital stocks in the U.S., the EU and China lead to larger capital imports by Japan. Consequently, Japan's capital stock and national income is also higher compared to the base case. The increase in wages during the transition lowers payroll tax rates slightly since 
labor supply remains unaffected. However, the average wage tax rate increases due to the higher growth in general government expenditures arising from higher output growth.

As the welfare effects in Table 15 indicate, initially middle-aged people lose from this policy reform in all four regions. In the U.S., the EU, and China this reflects the cut in pension replacement rates. People now receive lower benefits than under the baseline scenario. In Japan the losses stem from the increases in the average wage tax rate. Initial older cohorts in the four regions are almost unaffected. Initial young and future cohorts, however, gain in all four regions. The reason is mainly the reduction in payroll and wage tax rates in the U.S., the EU, and China and the increased wages that outweigh the benefit losses. In Japan, the welfare gains of the lowand middle-income classes also stem from the reduction in payroll taxes and the higher wages. The highest income classes are adversely affected by the increase in the wage tax rate.

\section{Privatizing Pensions}

Our final reform is complete pension privatization, which we model as the elimination of any new public pension benefit accrual coupled with the establishment of individual accounts. The reform entails paying off all accrued benefits to all those retired in 2004 and to all those working in 2004 when they reach retirement. To approximate this payoff of accrued benefits we pay all initial retirees their full benefits over time and pay post-2004 retirees benefits in retirement whose values are linearly phased out over a 45-year period starting in 2004. Thus, the members of the cohort retiring in 2005 receive in public pension benefits 44/45ths of what they would otherwise have received. The members of the cohort retiring in 2006 receive 43/45ths of what they would have received, etc.

We finance the move to individual accounts via consumption taxation. Specifically, we completely eliminate those payroll taxes used to finance state pensions and impose a new consumption tax in each region to pay, over time, all accrued benefits. By 2078 all accrued pension benefits have been paid off, so the new consumption tax rates from that point on are zero.

The key feature of the reform is not "privatization" per se, but rather the intergenerational redistribution associated with moving to private accounts. The redistribution comprises three element. First, the shift from payroll to consumption taxation reduces the tax burden on current 
and future workers and shifts it onto current retirees. Second, paying current workers (those working in 2004) when they reach retirement only their accrued state pension benefits rather than their projected benefits represents a cut in transfer payments that hurts those workers but benefits future workers who would otherwise have had to help pay for those benefits. Third, factor price changes arising from this policy help later generations at the cost of hurting earlier ones. Specifically, later generations benefit from higher real wages, while earlier generations lose from receiving lower returns on their assets.

There is no need to formally model the private accounts in which agents would be forced to save as part of this privatization reform. The reason is that our agents face no liquidity constraints. Hence, they are free to borrow against their private account balances if they wish to consume more than their disposable income net of contributions to these accounts. Consequently, forcing our agents to save has no impact on their behavior. ${ }^{7}$

In the U.S., the additional consumption tax rate needed to pay off accrued pension benefits is initially 6.8 percent and gradually declines thereafter. The U.S. payroll tax rate declines immediately by 7.8 percentage points. Over the transition, the payroll tax rate rises by 2.7 percentage points since expenses for health care and disability insurance grow.

In the EU, the added consumption tax rate has an initial value of 15.0 percent and then declines. Because of this reform, the payroll tax is reduced by 14.6 percentage points in year 2004 and rises to a maximum of 13.9 percent in 2075. In Japan, the consumption tax rate is initially 11.1 percent. It then rises to a maximum of 12.7 percent in 2016 before declining. The payroll tax is 12.1 percentage points lower in 2004. And the maximum value reached is 15.7 percent in 2050. Finally, the initial rate of the new consumption tax in China is 10.5 percent. The payroll tax rates is initially reduced by 8 percentage points and rises to its maximum value of 5.5 percent in 2075 .

Of course,since part of the tax burden is shifted from payroll taxes towards consumption

\footnotetext{
${ }^{7}$ Including liquidity constraints would require solving our agents' utility maximization problems using dynamic programming. Doing so would be much more time consuming. It would also introduce a degree of approximation error into the solution that we avoid with our current formulation in which we find the solutions to the first order conditions and budget constraints of our agents to a very high degree of precision using Gauss-Seidel iteration.
} 
taxes, the burden on younger households falls and that on the elderly rises. The intergenerational redistribution associated with the consumption tax depresses aggregate consumption, which permits an increase in national saving and capital formation. The long-run consequences of this reform are dramatic in all three regions. Relative to the base case simulations, the year 2100 capital stock increases by 87.6 percent in the U.S., by 81.1 percent in the E.U., by 90.4 percent in Japan, and by 83.2 percent in China.

The higher capital stocks increase gross wages, which rise by 2100 by approximately 18 percent in all four regions. The combination of higher gross wages and reduced payroll and wage taxes boosts net wages, which almost double in the four regions. The reductions in labor supplies in the four regions, reported in Tables 4 to 7 , are a direct consequence of the positive income effects experienced by younger generations. Finally, capital accumulation leads to lower year-2100 interest rates.

Of course, the advantageous macroeconomic effects of privatization come at a cost, which is shown in Table 16. The reform entails a major redistribution from older generations in all four economies towards younger and future generations. The intergenerational and intragenerational redistribution is less severe in the U.S. compared to the EU, Japan and China, whose initial consumption tax rates are much higher.

The elderly are hurt because they are now forced to pay for their pension benefits via the consumption tax. Younger and future generations benefit enormously from the policy since they face a much lower payroll tax burdens during their working years and experience much higher wages. Consider middle-earning agents in the U.S. The oldest such agents included in Table 16 those born in 1920 experience a 2.9 percent reduction in welfare. In contrast, the youngest such agents included in the table - those born in 2030 - enjoy a 12.2 percent rise in welfare. The corresponding welfare losses and gains experienced by the 1920 and 2030 middle classes are 6.1 percent and 23.5 percent in the EU, 5.3 percent and 15.9 percent in Japan, and 6.3 percent and 13.3 percent in China.

Another key feature of Table 16 is that the poor initial elderly experience larger welfare losses than the middle class or rich initial elderly. The explanation for this differential welfare loss 
is that both the poor and rich elderly are constrained with respect to their consumption of leisure because they are both fully retired. However, the rich elderly are consuming a lot more than the poor. Hence, while both the rich and the poor experience roughly the same percentage reduction in consumption from the imposition of the consumption tax, the impact on their utilities are not the same because a) their initial consumption-leisure ratios differ and b) utility is not separable with respect to the two arguments.

\section{Conclusion}

The developed world and China all face enormous demographic changes which will greatly challenge their already overly stressed fiscal institutions. Fortunately, our dynamic life-cycle model suggests there may be a macroeconomic silver lining to this very gray demographic cloud. The silver lining is China, whose continued rapid acquisition of technology and human capital and extraordinarily high rate of saving can dramatically raise the world's supply of capital. Assuming the developed world's capital market remains open, China will gradually become the developed world's major source of capital.

Indeed, assuming China attains the developed world's living standard by the middle of this century and also maintain its very high propensity to save, it will raise real wages in the developed world by 40 percent. This is over and above real wage increases arising from technological change. Even were China to gradually adopt Western spending habits, real wages at mid Century will be 16 percent higher than is currently the case. This again is above and beyond what technological change can be expected to deliver.

Moreover, China's contribution to the developed world's own development is positive in the short as well as long runs. Even though capital initially moves from the developed world to China, there are no major short-run reductions in developed world real wages. The reason is that the prospect of higher future real wages leads developed world workers to supply less current labor. This keeps initial developed world capital-labor ratios and the real wages on which they depend from falling.

Absent China, our model suggests a very gradual decline in the developed world's capital intensivity with real wages per unit of human capital 4 percent lower at the end of the Century 
than they are today. This is much less ominous news than we delivered in previous studies that omitted China. The reason is that we now incorporate government investment, which implies more developed world saving.

In addition to examining China's role in world economic development and incorporating government investment, this study has entertained a variety of demographic and fiscal scenarios. Our demographic scenarios, which we apply to all four regions simultaneously, are a) maintaining fertility rates at their current generally very low levels for much longer than governments now project, b) increasing longevity at faster than projected rates, and c) immediately and permanently doubling rates of immigration.

Each of these demographic changes has very little impact on the overall macroeconomic situation, but each makes a non-trivial difference to where payroll tax rates end up. For example, Japan's payroll tax rate ends up 25 percent higher at the end of the century if its fertility rate fails to rise to the now-projected 2050 level; the EU's payroll tax rate ends 5 percentage points higher in 2030 if EU life expectancy rises by 3 years more by 2050 than now expected; and the U.S. payroll tax rate is reduced by 1 percent in 2050 if it doubles its rate of immigration.

Our policy simulations raised the rate of growth of health expenditures over the next quarter Century, switched, at the margin, to income-tax finance of government pension benefits, financed future increases in aggregate pension benefits via increases in income taxes rather than payroll taxes, and privatized state pension systems by paying off accrued pension benefits with a consumption tax. Each of these policies has important impacts on the macro economy. But the one with the biggest impact is the privatization of state pensions, which more than doubles long-run ratios of physical capital per unit of human capital and raises long-run real wages by roughly a quarter. The policy delivers major benefits to future generations, both because of the higher wages they earn and the dramatically lower payroll tax rates that they face.

To conclude, there is no reason to believe that China is currently eating our lunch or will do so in the near future. On the contrary, there is good reason to believe that China is in the process of taking us to diner by slowly but surely becoming the world's biggest saver and the developed world's major supplier of capital. 


\section{References}

Altig, D., A.J. Auerbach, L.J. Kotlikoff, K.A. Smetters and J. Walliser, 2001, "Simulating Fundamental Tax Reform in the United States," American Economic Review 91, 574-595.

Auerbach, A. J. and L. J. Kotlikoff, 1987, Dynamic Fiscal Policy, Cambridge, England: Cambridge University Press.

Auerbach, A. J. and L. J. Kotlikoff, 1983, "An Examination of Empirical Tests of Social Security and Savings," in E. Helpman et. al., eds., Social Policy Evaluation: An Economic Perspective, San Diego, Ca.: Academic Press.

Bohn, H., 2001, "Social Security and Demographic Uncertainty: The Risk Sharing Properties of Alternative Policies," in John Campbell and Martin Feldstein, eds., Risk Aspects of Investment Based Social Security Reform, Chicago: University of Chicago Press, 203-241.

Blöndal, S. and S. Scarpetta, 1999, "The Retirement Decision in OECD Countries," Economics Department Working Paper No. 202, OECD, Paris.

Cooley, T. F. and J. Soares, 1999a, "A Positive Theory of Social Security Based on Reputation," Journal of Political Economy 107, 135-60.

Cooley, T. F. and J. Soares, 1999b, "Privatizing Social Security," Review of Economic Dynamics 2, 731- 55 .

De Nardi, M., Imrohoroglu, S. and T. J. Sargent, 1999, "Projected U.S. Demographics and Social Security," Review of Economic Dynamics 2, 575-615.

Docteur, E. and H. Oxley, 2003, "Health-Care Systems: Lessons from the Reform Experience," Economics Department Working Paper No. 374, OECD, Paris.

European Commission, 2003, The Budgetary Challenges Posed by Ageing Populations, European Economy: Reports and Studies No. 4 2001, Brussels. 
European Commission, 2005, Statistical Annex to European Economy, Spring 2005, http://europa.eu.int/comm/economy_finance/publications/european_economy/ statisticalannex_en.htm, July 1, 2005.

Fehr, H. and C. Habermann, 2005, "Risk Sharing and Efficiency Implications of Progressive Pension Arrangements," mimeo, University of Wuerzburg.

Fehr, H., G. Halder, S. Jokisch and L.J. Kotlikoff, 2003, "A Simulation Model for the Demographic Transition in the OECD - Data Requirements, Model Structure and Calibration," Wuerzburg Economic Papers No. 45, University of Wuerzburg.

Fehr, H., S. Jokisch and L.J. Kotlikoff, 2004a, "Fertility, Mortality, and the Developed World's Demographic Transition," CESifo Working Paper No. 1326, Munich.

Fehr, H., S. Jokisch and L.J. Kotlikoff, 2004b, "The Role of Immigration in Dealing with Developed World's Demographic Transition," Finanzarchiv 60, 296-324.

Fehr, H., S. Jokisch and L.J. Kotlikoff, 2005, "The Developed World's Demographic Transition - The Roles of Capital Flows, Immigration, and Policy," in: R. Brooks and A. Razin, eds., Social Security Reform - Financial and Political Issues in International Perspective, Cambridge, 11-43.

Feldstein, M.S., 1974, "Social Security, Induced Retirement, and Aggregate Capital Accumulation," Journal of Political Economy 82, 905-926.

Heckman, J. J., Lochner, L., and C. Taber, 1998, "Explaining Rising Wage Inequality: Explorations with a Dynamic General Equilibrium Model of Labor Earnings with Heterogeneous Agents," Review of Economic Dynamics 1, 1-58.

Huang, H., Imrohoroglu, S. and T. Sargent, 1997, "Two Computational Experiments to Fund Social Security," Macroeconomic Dynamics 1, 7-44.

Hubbard, G. R. and K. L. Judd, 1987, "Social Security and Individual Welfare: Precautionary Saving, Borrowing Constraints, and the Payroll Tax," American Economic Review 77, 63046. 
Huggett, M. and G. Ventura, 1999, "On the Distributional Effects of Social Security Reform," Review of Economic Dynamics 2, 498-531.

Imrohoroglu, A., Imrohoroglu, S. and D. H. Joines, 1999, "Social Security in an Overlapping Generations Economy with Land," Review of Economic Dynamics, 2, 638-65.

Imrohoroglu, A., Imrohoroglu, S. and D. H. Joines, 1995, "A Life Cycle Analysis of Social Security," Economic Theory 6, 83-114.

Kotlikoff, L. J., 1979, "Social Security and Equilibrium Capital Intensity," Quarterly Journal of Economics, 93, 233-54.

Kotlikoff, L. J., 1996, "Privatizing Social Security: How It Works and Why It Matters," in: J. M. Poterba, ed., Tax Policy and the Economy 10, 1-32.

Kotlikoff, L. J., Smetters, K. and J. Walliser, 1998a, "The Economic Impact of Privatizing Social Security,” in: H. Siebert, ed., Redesigning Social Security (J.C.B. Mohr, Tübingen) 327-48.

Kotlikoff, L. J., Smetters, K. and J. Walliser, 1998b, "Social Security: Privatization and Progressivity," American Economic Review 88, 137-41.

Kotlikoff, L. J., Smetters, K. and J. Walliser, 1999, "Privatizing Social Security in the U.S. Comparing the Options," Review of Economic Dynamics 2, 532-74.

Kotlikoff, L. J., Smetters, K. and J. Walliser, 2002, "Distributional Effects in a General Equilibrium Analysis of Social Security," in: M. S. Feldstein and J. Liebman, eds., The Distributional Effects of Social Security Reform (University of Chicago Press, Chicago) 327-61.

Kotlikoff, L.J., K.A. Smetters and J. Walliser, 2001, "Finding a Way out of America's Demographic Dilemma," NBER Working Paper No. 8258, Cambridge.

Nashiyama, S. and K. Smetters, 2004, "Consumption Taxes and Economic Efficiency in a Stochastic OLG Economy," Journal of Political Economy, forthcoming.

OECD (2001): Ageing and Income: Financial Resources and Retirement in 9 OECD Countries, Paris. 
OECD (2002): China in the World Economy: The Domestic Policy Challenges, Paris.

OECD (2003a): Education at a glance: OECD Indicators 2003, Paris.

OECD (2003b): Financing Education - Investments and Returns: Analysis of the world education indicators, 2002 Edition, Paris.

OECD (2003c): Revenue Statistics 1965-2002, Paris.

Raffelhüschen, B., 1989, Anreizwirkungen des Systems der sozialen Alterssicherung. Eine dynamische Simulationsanalyse, Frankfurt a.M., Peter Lang.

Raffelhüschen, B., 1993, "Funding Social Security Through Pareto Optimal Conversion Policies," in: B. Felderer, ed., Public Pension Economics, Journal of Economics/Zeitschrift für Nationalökonomie, Suppl. 7, 105-31.

Siegel, J., 2005, "The Future for Investors," New York: Crown Business.

Seidman, L. S., 1986, "A Phase-Down of Social Security: The Transition in a Life Cycle Growth Model," National Tax Journal, 97-107.

Smetters, K. and J. Walliser, 2004, "Opting Out of Social Security," Journal of Public Economics 88, 1295-1306.

Social Security Advisory Board, 1999, The 1999 Technical Panel on Assumptions and Methods, Social Security Advisory Board, Washington, D.C.

Summers, L.H., 1981, "Capital Taxation and Accumulation in a Life Cycle Growth Model," American Economic Review 71, 533-544.

Tuljapurkar, S., N. Li and C. Boe, 2000, "A universal pattern of mortality decline in the G7 countries," Nature 405, 789-792.

United Nations Population Division (UNPD), 2003, World Population Prospects: The 2002 Revision, http://esa.un.org/unpp/, (June 11, 2003). 
United Nations Population Division (UNPD), 2005, World Population Prospects: The 2004 Revision, http://esa.un.org/unpp/, (June 29, 2005).

Whitehouse, E., 2002, "Pension Systems in 15 Countries Compared: The Value of Entitlements," Discussion Paper 02/04, Centre for Pensions and Superannuation, Sydney.

WHO, 2004, The World Health Report 2004, Geneva. 
Figure 1: The individual life-cycle

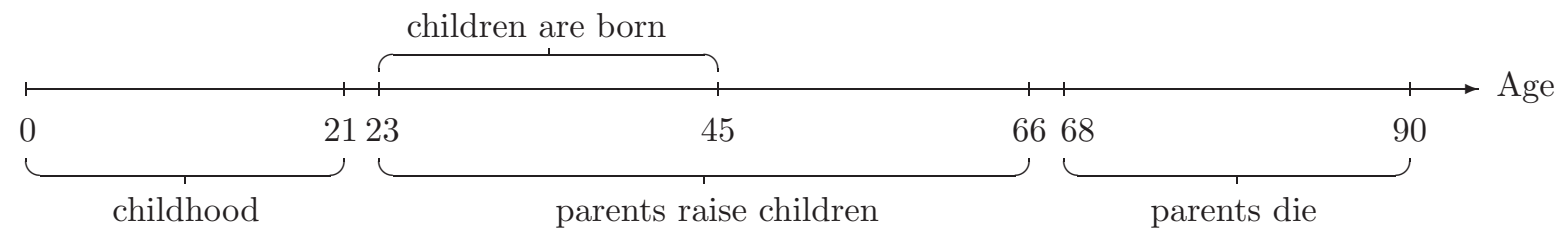

Table 1: Comparing Actual and Simulated Population Projections

Population Projection U.S.

\begin{tabular}{|c|c|c|c|c|c|c|c|c|}
\hline \multicolumn{2}{|l|}{ Year } & 2000 & 2010 & 2020 & 2030 & 2040 & 2050 & 2100 \\
\hline \multicolumn{9}{|c|}{ Fertility Rate } \\
\hline \multirow{2}{*}{\multicolumn{2}{|c|}{$\begin{array}{l}\text { Model } \\
\text { Official }^{a}\end{array}$}} & 2.11 & 2.05 & 2.00 & 1.95 & 1.90 & 1.85 & 1.77 \\
\hline & & 2.11 & 2.08 & 2.03 & 1.95 & 1.89 & 1.85 & - \\
\hline \multicolumn{9}{|c|}{ Life Expectancy at Birth } \\
\hline \multicolumn{2}{|c|}{ Model } & 81.7 & 82.1 & 82.5 & 83.0 & 83.4 & 83.8 & 83.8 \\
\hline \multicolumn{2}{|c|}{ Official $^{a}$} & 77.1 & 78.3 & 79.1 & 79.9 & 81.0 & 81.6 & - \\
\hline \multicolumn{9}{|c|}{ Total Population ${ }^{b}$} \\
\hline \multicolumn{2}{|c|}{ Model } & 276.2 & 307.3 & 340.0 & 366.4 & 385.8 & 400.3 & 442.0 \\
\hline \multicolumn{2}{|c|}{ Official $^{a}$} & 285.0 & 314.9 & 344.3 & 370.4 & 391.4 & 408.7 & - \\
\hline \multicolumn{9}{|c|}{ Age Structure $^{c}$} \\
\hline \multirow[t]{2}{*}{$<15$} & Model & 21.6 & 20.1 & 19.7 & 18.5 & 18.2 & 17.8 & 15.9 \\
\hline & Official $^{a}$ & 21.8 & 20.5 & 20.0 & 19.3 & 18.5 & 17.9 & - \\
\hline \multirow[t]{2}{*}{$15-64$} & Model & 66.2 & 67.2 & 64.0 & 61.4 & 61.7 & 62.1 & 60.7 \\
\hline & Official $^{a}$ & 65.9 & 66.6 & 64.1 & 61.5 & 61.7 & 62.1 & _ \\
\hline \multirow[t]{2}{*}{$65-90$} & Model & 12.2 & 12.7 & 16.3 & 20.1 & 20.2 & 20.1 & 23.3 \\
\hline & Official ${ }^{a}$ & 12.3 & 12.8 & 15.9 & 19.2 & 19.8 & 20.0 & - \\
\hline
\end{tabular}


Population Projection EU

\begin{tabular}{|c|c|c|c|c|c|c|c|c|}
\hline \multicolumn{2}{|l|}{ Year } & 2000 & 2010 & 2020 & 2030 & 2040 & 2050 & 2100 \\
\hline \multicolumn{9}{|c|}{ Fertility Rate } \\
\hline \multicolumn{2}{|c|}{ Model } & 1.46 & 1.53 & 1.60 & 1.67 & 1.74 & 1.82 & 1.82 \\
\hline \multicolumn{2}{|c|}{ Official $^{d}$} & 1.58 & 1.61 & 1.68 & 1.77 & 1.84 & 1.85 & - \\
\hline \multicolumn{9}{|c|}{ Life Expectancy at Birth } \\
\hline \multicolumn{2}{|c|}{ Model } & 82.2 & 82.7 & 83.2 & 83.6 & 84.1 & 84.6 & 84.6 \\
\hline \multicolumn{2}{|c|}{ Official $^{d}$} & 78.6 & 80.0 & 81.1 & 82.0 & 83.0 & 83.6 & - \\
\hline \multicolumn{9}{|c|}{ Total Population ${ }^{b}$} \\
\hline \multicolumn{2}{|c|}{ Model } & 376.4 & 385.8 & 390.9 & 391.1 & 384.1 & 372.1 & 340.6 \\
\hline \multicolumn{2}{|c|}{ Official $^{a}$} & 377.3 & 383.2 & 384.4 & 382.8 & 377.8 & 369.8 & - \\
\hline \multicolumn{9}{|c|}{ Age Structure ${ }^{c}$} \\
\hline \multirow[t]{2}{*}{$<15$} & Model & 16.9 & 15.3 & 14.5 & 14.3 & 14.3 & 14.8 & 16.5 \\
\hline & Official $^{a}$ & 16.7 & 15.3 & 14.4 & 14.4 & 14.7 & 15.0 & - \\
\hline \multirow[t]{2}{*}{$15-64$} & Model & 66.9 & 66.9 & 64.7 & 60.8 & 57.7 & 57.2 & 59.7 \\
\hline & Official $^{a}$ & 66.9 & 66.5 & 64.7 & 60.8 & 57.5 & 56.7 & - \\
\hline \multirow[t]{2}{*}{$65-90$} & Model & 16.2 & 17.8 & 20.8 & 24.9 & 28.0 & 28.0 & 23.9 \\
\hline & Official $^{a}$ & 16.3 & 18.2 & 21.0 & 24.7 & 27.8 & 28.3 & - \\
\hline
\end{tabular}

Population Projection Japan

\begin{tabular}{|c|c|c|c|c|c|c|c|c|}
\hline \multicolumn{2}{|l|}{ Year } & 2000 & 2010 & 2020 & 2030 & 2040 & 2050 & 2100 \\
\hline \multicolumn{9}{|c|}{ Fertility Rate } \\
\hline \multicolumn{2}{|c|}{ Model } & 1.28 & 1.37 & 1.47 & 1.56 & 1.66 & 1.75 & 1.91 \\
\hline \multicolumn{2}{|c|}{ Official $^{a}$} & 1.32 & 1.37 & 1.49 & 1.68 & 1.81 & 1.85 & - \\
\hline \multicolumn{9}{|c|}{ Life Expectancy at Birth } \\
\hline \multicolumn{2}{|c|}{ Model } & 83.8 & 84.6 & 85.4 & 86.2 & 87.0 & 87.8 & 87.8 \\
\hline \multicolumn{2}{|c|}{ Official $^{a}$} & 81.6 & 83.5 & 85.1 & 86.6 & 87.7 & 88.1 & - \\
\hline \multicolumn{9}{|c|}{ Total Population ${ }^{b}$} \\
\hline \multicolumn{2}{|c|}{ Model } & 126.7 & 128.9 & 127.1 & 121.8 & 114.2 & 108.8 & 84.8 \\
\hline \multicolumn{2}{|c|}{ Official $^{a}$} & 127.0 & 128.0 & 125.6 & 121.0 & 115.7 & 109.7 & - \\
\hline \multicolumn{9}{|c|}{ Age Structure ${ }^{c}$} \\
\hline \multirow[t]{2}{*}{$<15$} & Model & 14.6 & 13.4 & 12.5 & 11.9 & 12.5 & 12.9 & 16.0 \\
\hline & Official $^{a}$ & 14.6 & 13.6 & 12.4 & 11.8 & 12.6 & 13.0 & - \\
\hline \multirow[t]{2}{*}{$15-64$} & Model & 68.2 & 64.1 & 59.2 & 58.1 & 55.0 & 52.1 & 56.3 \\
\hline & Official $^{a}$ & 68.2 & 64.0 & 59.5 & 57.8 & 53.0 & 50.4 & - \\
\hline \multirow[t]{2}{*}{ 65-90 } & Model & 17.2 & 22.5 & 28.2 & 30.0 & 32.5 & 35.0 & 27.7 \\
\hline & Official $^{a}$ & 17.2 & 22.4 & 28.1 & 30.4 & 34.4 & 36.5 & - \\
\hline
\end{tabular}


Population Projection China

\begin{tabular}{|c|c|c|c|c|c|c|c|c|}
\hline \multicolumn{2}{|l|}{ Year } & 2000 & 2010 & 2020 & 2030 & 2040 & 2050 & 2100 \\
\hline \multicolumn{9}{|c|}{ Fertility Rate } \\
\hline \multicolumn{2}{|c|}{ Model } & 1.62 & 1.67 & 1.71 & 1.76 & 1.80 & 1.85 & 2.01 \\
\hline \multicolumn{2}{|c|}{ Official $^{e}$} & 1.32 & 1.37 & 1.49 & 1.68 & 1.81 & 1.85 & - \\
\hline \multicolumn{9}{|c|}{ Life Expectancy at Birth } \\
\hline \multicolumn{2}{|c|}{ Model } & 75.8 & 76.7 & 77.5 & 78.4 & 79.3 & 80.2 & 80.2 \\
\hline \multicolumn{2}{|c|}{ Official $^{e}$} & 71.5 & 72.6 & 73.8 & 75.3 & 77.1 & 78.7 & - \\
\hline \multicolumn{9}{|c|}{ Total Population ${ }^{b}$} \\
\hline \multicolumn{2}{|c|}{ Model } & 1273.1 & 1360.7 & 1455.0 & 1490.7 & 1481.3 & 1430.8 & 1181.8 \\
\hline \multicolumn{2}{|c|}{ Official $^{e}$} & 1274.0 & 1354.5 & 1423.9 & 1446.5 & 1433.4 & 1392.3 & - \\
\hline \multicolumn{9}{|c|}{ Age Structure ${ }^{c}$} \\
\hline \multirow[t]{2}{*}{$<15$} & Model & 24.6 & 19.5 & 18.3 & 16.5 & 15.6 & 16.3 & 18.5 \\
\hline & Official $^{e}$ & 24.8 & 19.5 & 18.4 & 16.9 & 15.6 & 15.7 & - \\
\hline \multirow[t]{2}{*}{$15-64$} & Model & 68.6 & 73.3 & 70.6 & 67.8 & 63.1 & 61.6 & 61.7 \\
\hline & Official ${ }^{e}$ & 68.4 & 72.2 & 69.7 & 66.8 & 62.1 & 60.7 & - \\
\hline \multirow[t]{2}{*}{$65-90$} & Model & 6.8 & 7.2 & 11.1 & 15.7 & 21.3 & 22.0 & 19.8 \\
\hline & Official $^{e}$ & 6.8 & 8.3 & 11.9 & 16.3 & 22.3 & 23.6 & - \\
\hline
\end{tabular}

${ }^{a}$ UNPD (2003), medium variant projections; ${ }^{b}$ in millions; ${ }^{c}$ in percent of total population;

${ }^{d}$ UNPD(2003), medium variant projections, Western Europe; ${ }^{e}$ UNPD (2005), medium variant projections. 
Table 2: Parameter Values of the Model

\begin{tabular}{llcccc}
\hline & Symbol & \multicolumn{3}{c}{ Value } \\
& & U.S. & EU & Japan & China \\
\hline Utility Function & & & & & \\
Time preference rate & $\theta$ & 0.01 & 0.00 & 0.01 & -0.13 \\
Intertemporal elasticity of substitution & $\gamma$ & & & 0.25 & \\
Intratemporal elasticity of substitution & $\rho$ & & & 0.4 & \\
Leisure preference parameter & $\alpha$ & & & 1.5 & \\
Production Function & & & & & \\
Technology level & $\phi$ & 1.01 & 1.01 & 1.01 & 0.24 \\
Capital share in production & $\varepsilon$ & & & 0.25 & \\
Technical progress & $\lambda$ & & & 0.01 & \\
Policy Parameters & & & & & \\
Consumption tax rate (in \%) & $\tau^{c}$ & 10.2 & 23.6 & 14.7 & 20.0 \\
Capital tax rate (in \%) & $\tau^{r}$ & 11.0 & 14.0 & 8.0 & 0.0 \\
Corporate tax rate (in \%) & $\tau^{k}$ & 12.0 & 18.0 & 16.0 & 0.0 \\
Expensing fraction (in \%) & $\epsilon$ & 0.0 & 20.0 & 40.0 & 0.0 \\
Debt (in \% of national income) & $B / Y$ & 33.3 & 38.9 & 41.4 & 10.0 \\
Age of retirement & & 63 & 60 & 60 & 60 \\
\hline
\end{tabular}


Table 3: The Year 2004 of the Baseline Path ${ }^{a}$

\begin{tabular}{|c|c|c|c|c|c|c|c|c|}
\hline & \multicolumn{4}{|c|}{ Model } & \multicolumn{4}{|c|}{ Official $^{b}$} \\
\hline & U.S. & $\mathrm{EU}$ & Japan & China & U.S. & $\mathrm{EU}$ & Japan & China \\
\hline \multicolumn{9}{|l|}{ National Income } \\
\hline Private consumption & 79.7 & 65.1 & 70.5 & 52.4 & 79.3 & 67.3 & 69.3 & 49.5 \\
\hline $\begin{array}{l}\text { Government purchases of goods } \\
\text { and services }\end{array}$ & 18.7 & 31.0 & 21.9 & 17.9 & 17.4 & 24.3 & 21.7 & 17.6 \\
\hline General public expenditures & 10.9 & 19.3 & 12.3 & 13.8 & - & - & - & - \\
\hline Aggregate education outlays & 5.9 & 6.0 & 4.4 & 2.1 & 5.9 & 6.0 & 4.3 & 2.1 \\
\hline Aggregate health benefits & 1.9 & 5.7 & 5.2 & 2.0 & 2.5 & 6.2 & 6.8 & 2.0 \\
\hline Current account & 2.8 & 8.3 & 13.8 & -16.1 & -6.1 & 0.5 & 4.5 & 1.9 \\
\hline \multicolumn{9}{|l|}{ Government Indicators } \\
\hline Social contributions received & 8.1 & 16.4 & 13.9 & 7.7 & 7.9 & 16.6 & 13.4 & 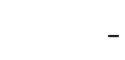 \\
\hline Aggregate pension benefits & 5.3 & 9.2 & 7.6 & 5.2 & 5.7 & 11.6 & 10.8 & 3.0 \\
\hline Aggregate health benefits & 1.9 & 5.7 & 5.2 & 2.0 & 2.5 & 6.2 & 6.8 & 2.0 \\
\hline Aggregate disability benefits & 0.9 & 1.5 & 1.1 & 0.0 & 0.9 & - & - & - \\
\hline Pension contribution rate ${ }^{c}$ & 7.7 & 14.2 & 12.1 & 8.0 & 10.6 & - & 17.3 & 11.0 \\
\hline Health-care contribution rate ${ }^{c}$ & 2.5 & 8.8 & 8.2 & 3.1 & 2.9 & - & 8.5 & 8.0 \\
\hline $\begin{array}{l}\text { Disability-insurance contribution } \\
\text { rate }^{c}\end{array}$ & 1.4 & 2.3 & 1.8 & 0.0 & 1.9 & - & - & - \\
\hline Interest payment on public debt ${ }^{c}$ & 3.3 & 3.8 & 4.1 & 1.0 & 3.0 & 3.5 & 3.7 & 0.8 \\
\hline Tax revenues ${ }^{c}$ & 20.3 & 30.3 & 21.9 & 15.8 & 20.6 & 31.0 & 19.1 & 14.8 \\
\hline Direct taxes & 12.2 & 14.9 & 11.5 & 5.3 & 12.5 & 15.1 & 8.9 & 2.8 \\
\hline Personal income taxes & 9.2 & 10.5 & 7.5 & 5.3 & 9.5 & 10.7 & 4.7 & 0.7 \\
\hline Wage taxes & 5.7 & 5.9 & 4.9 & 5.3 & - & - & - & - \\
\hline Capital taxes & 3.5 & 4.6 & 2.6 & 0.0 & - & - & - & - \\
\hline Corporate income taxes & 3.0 & 4.4 & 4.0 & 0.0 & 3.0 & 4.4 & 4.2 & 2.1 \\
\hline Indirect taxes & 8.1 & 15.4 & 10.4 & 10.5 & 8.1 & 15.9 & 10.2 & 12.0 \\
\hline \multicolumn{9}{|l|}{ Wage tax rates ${ }^{c}$} \\
\hline Average & 7.8 & 8.0 & 6.6 & 7.1 & - & - & - & - \\
\hline Marginal & 14.2 & 13.9 & 11.9 & 8.9 & - & - & - & - \\
\hline Capital-output ratio & 2.2 & 2.2 & 2.3 & 2.6 & - & - & - & \\
\hline Capital-labor ratio & 3.0 & 2.9 & 3.1 & 0.5 & - & - & - & \\
\hline Interest rate ${ }^{c}$ & 9.8 & 9.8 & 9.8 & 9.8 & - & - & - & 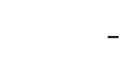 \\
\hline
\end{tabular}

${ }^{a}$ in percent of national income if not stated differently; ${ }^{b}$ European Commission (2005) for the U.S., the EU and Japan, OECD (2002) for China; ${ }^{c}$ in percent. 


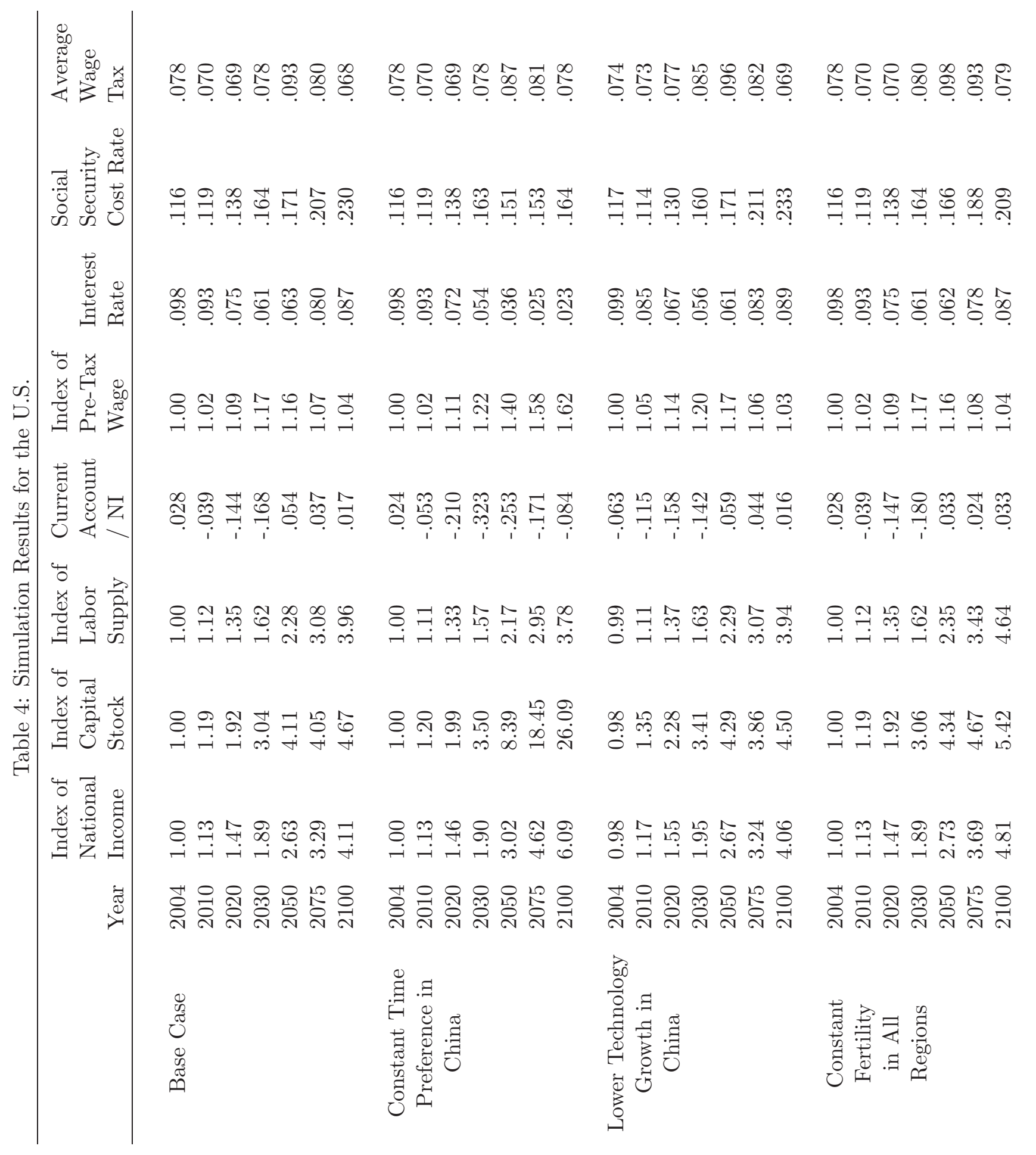




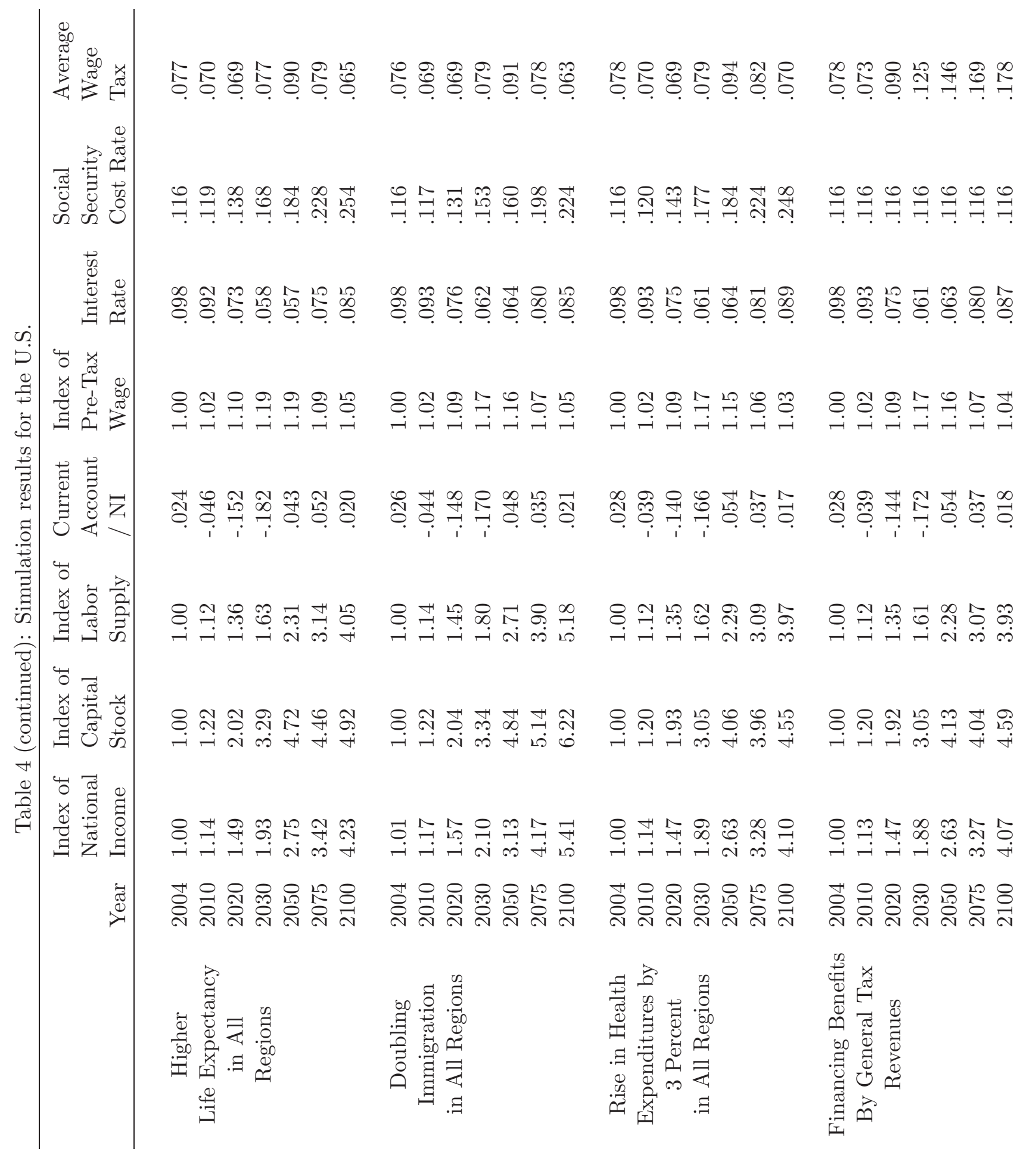




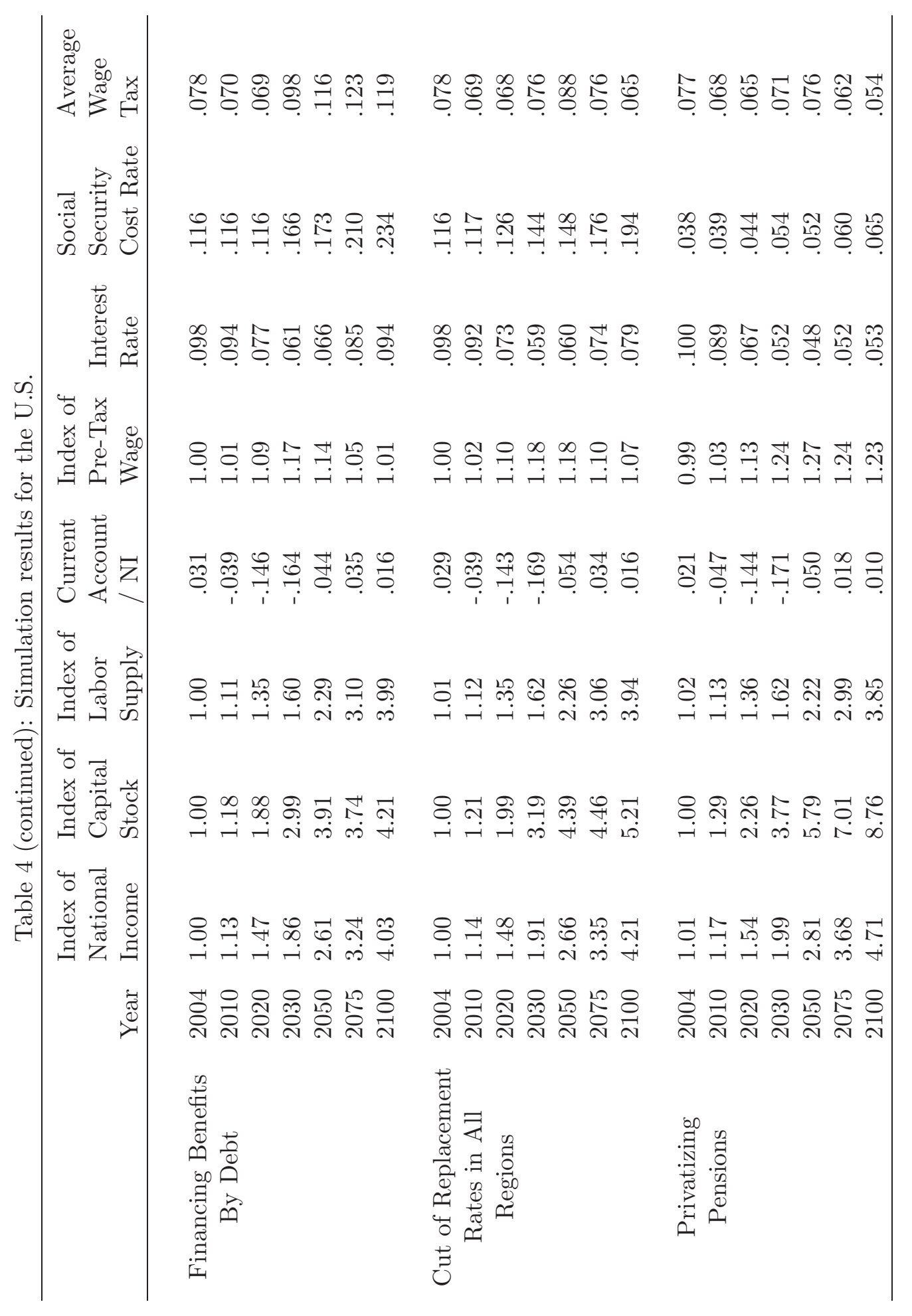




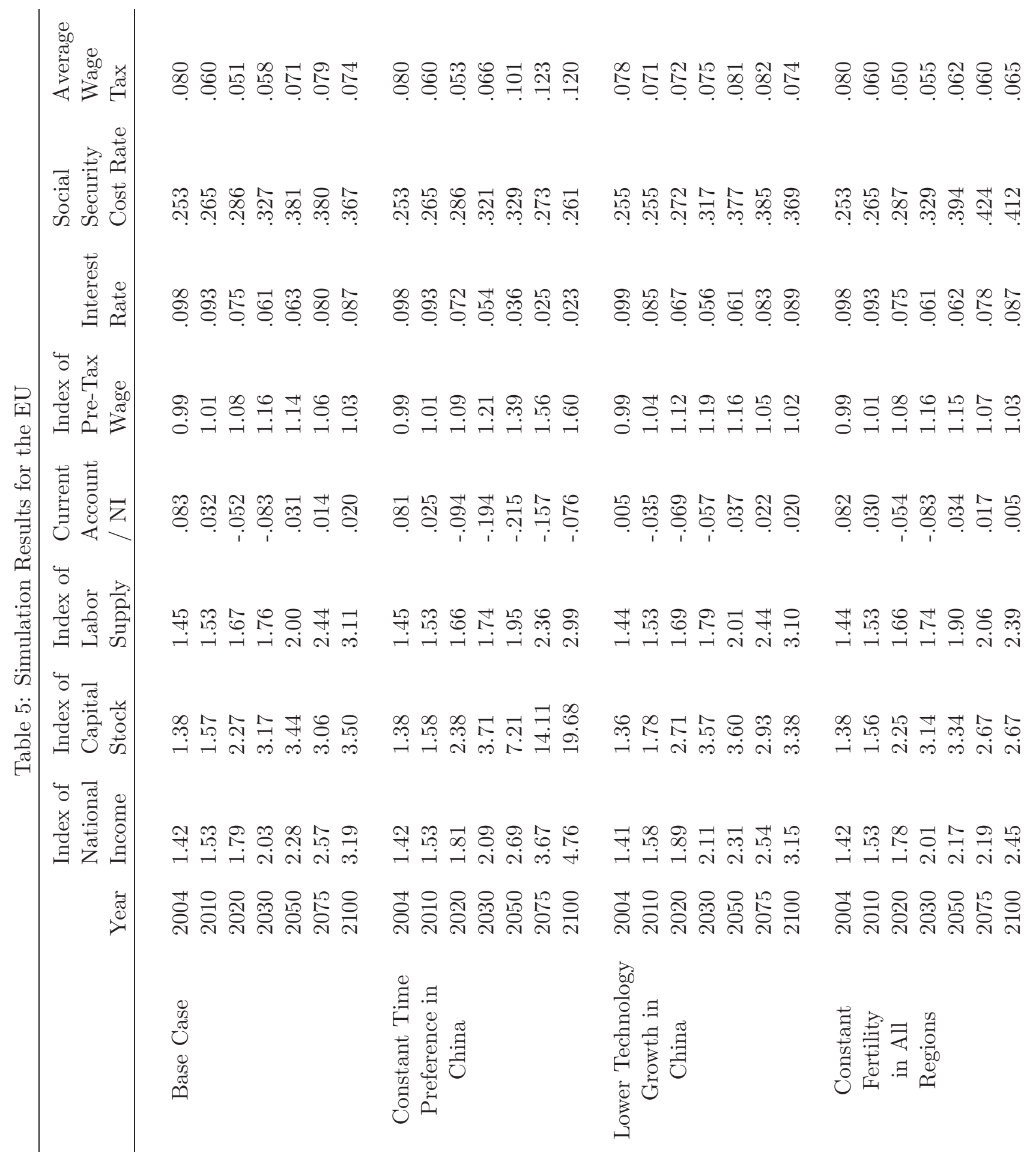




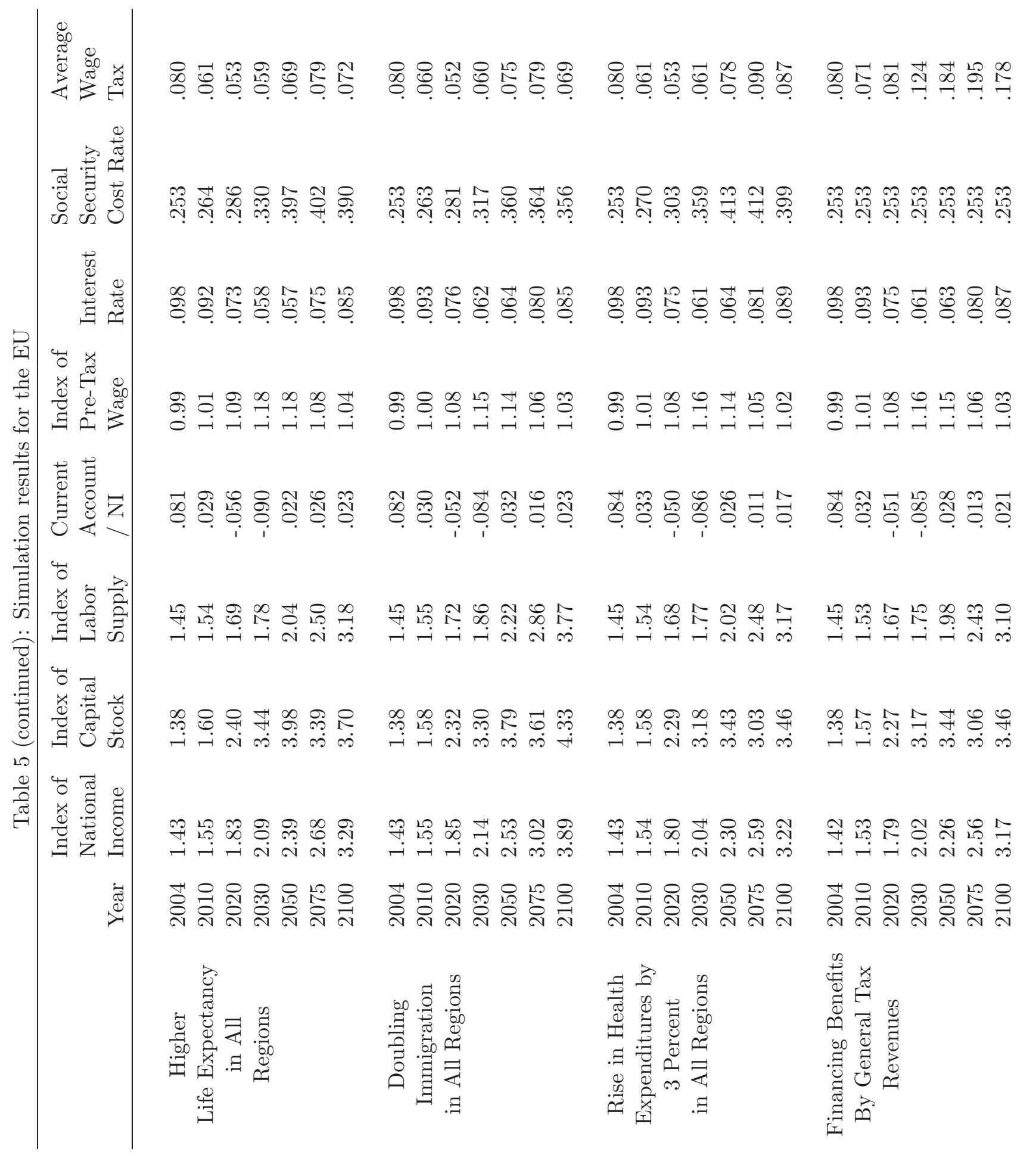




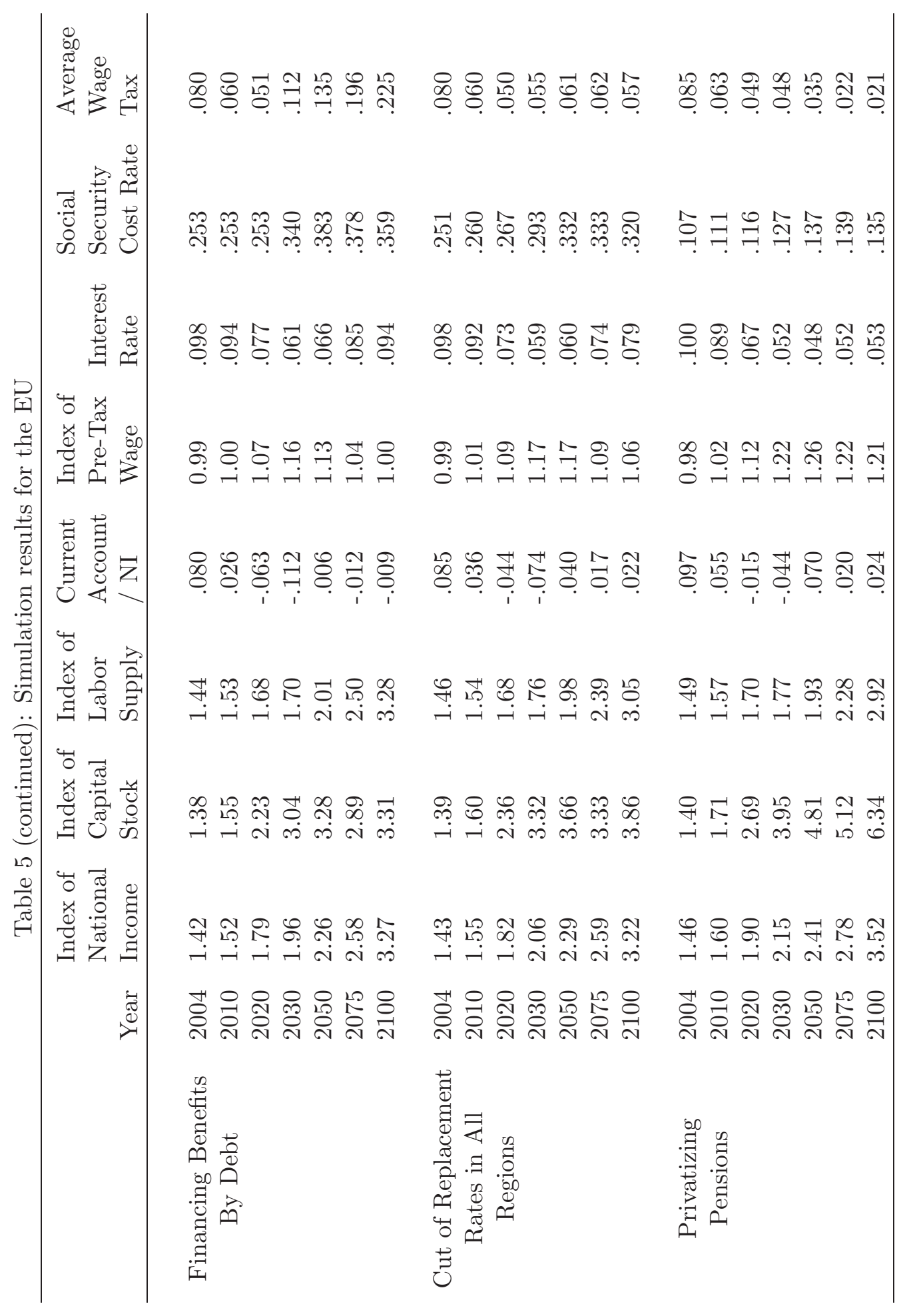




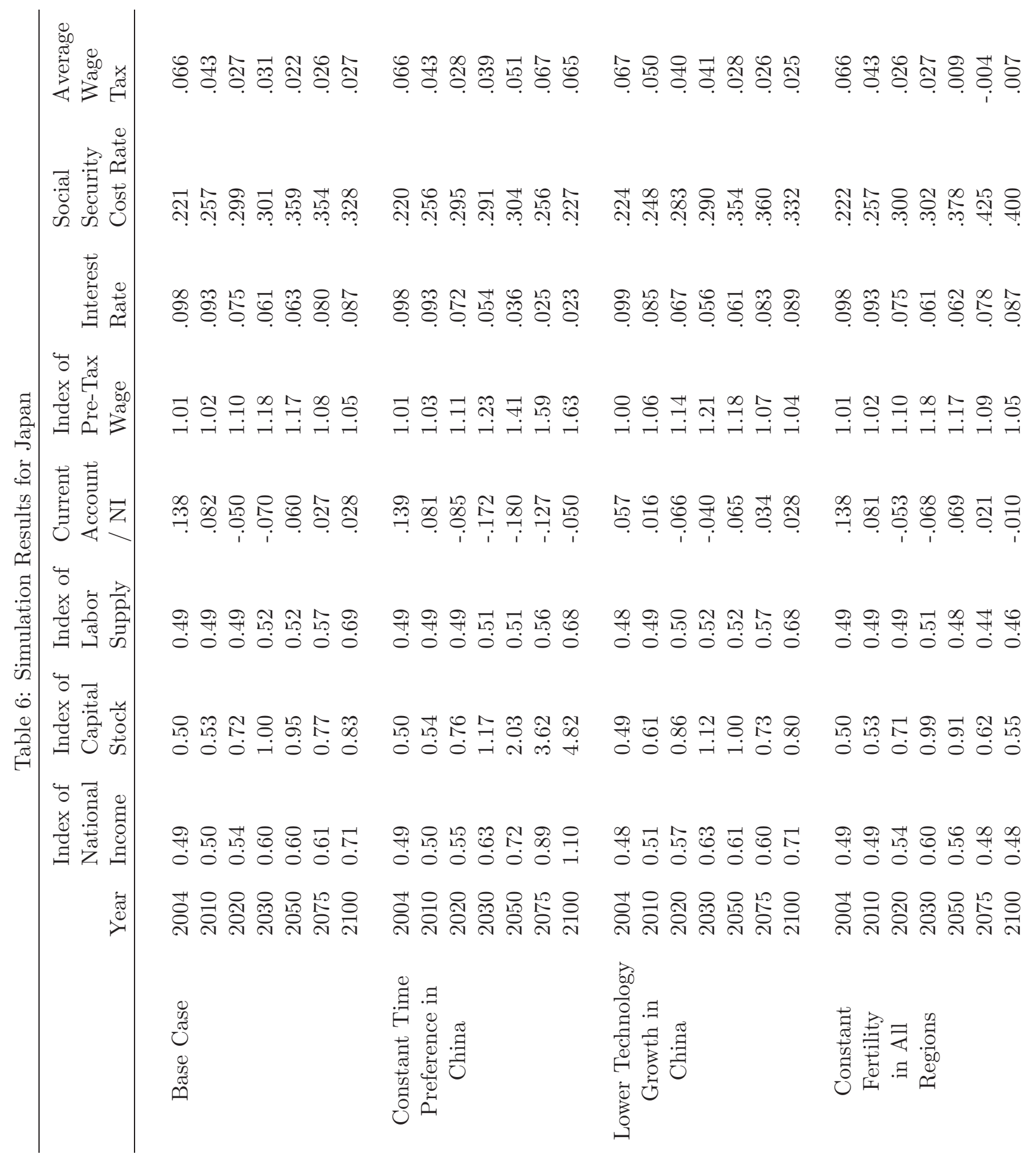




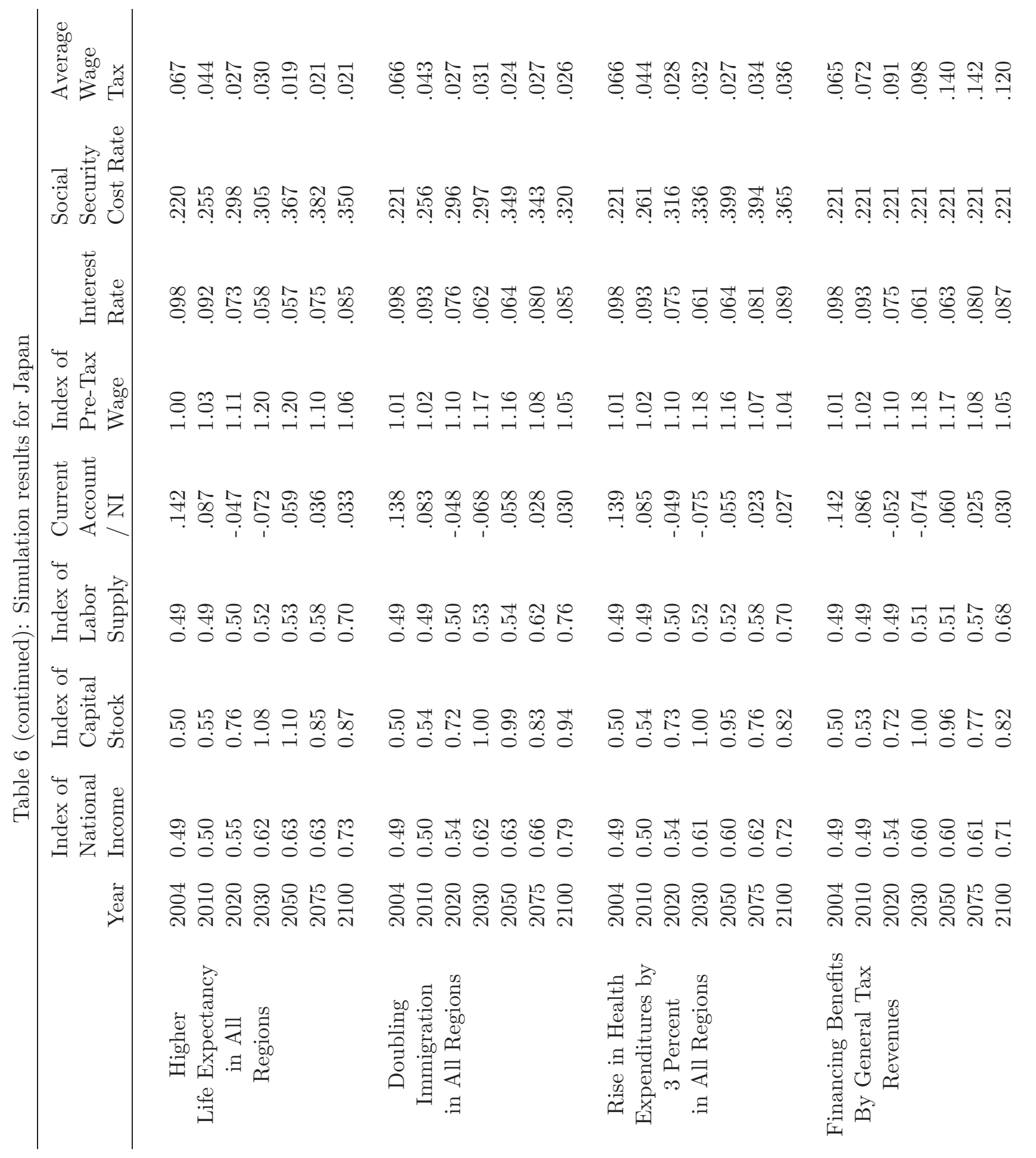




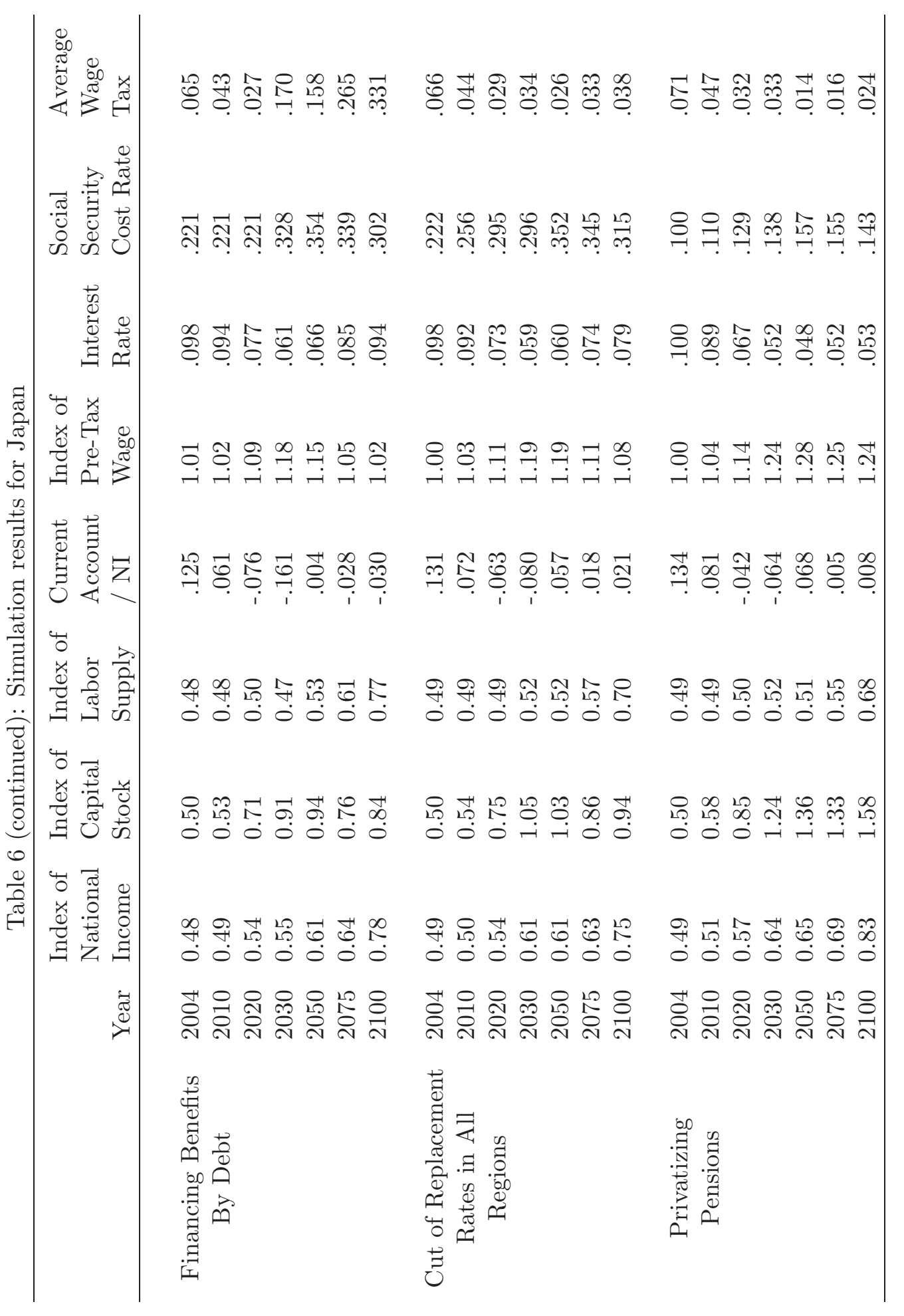




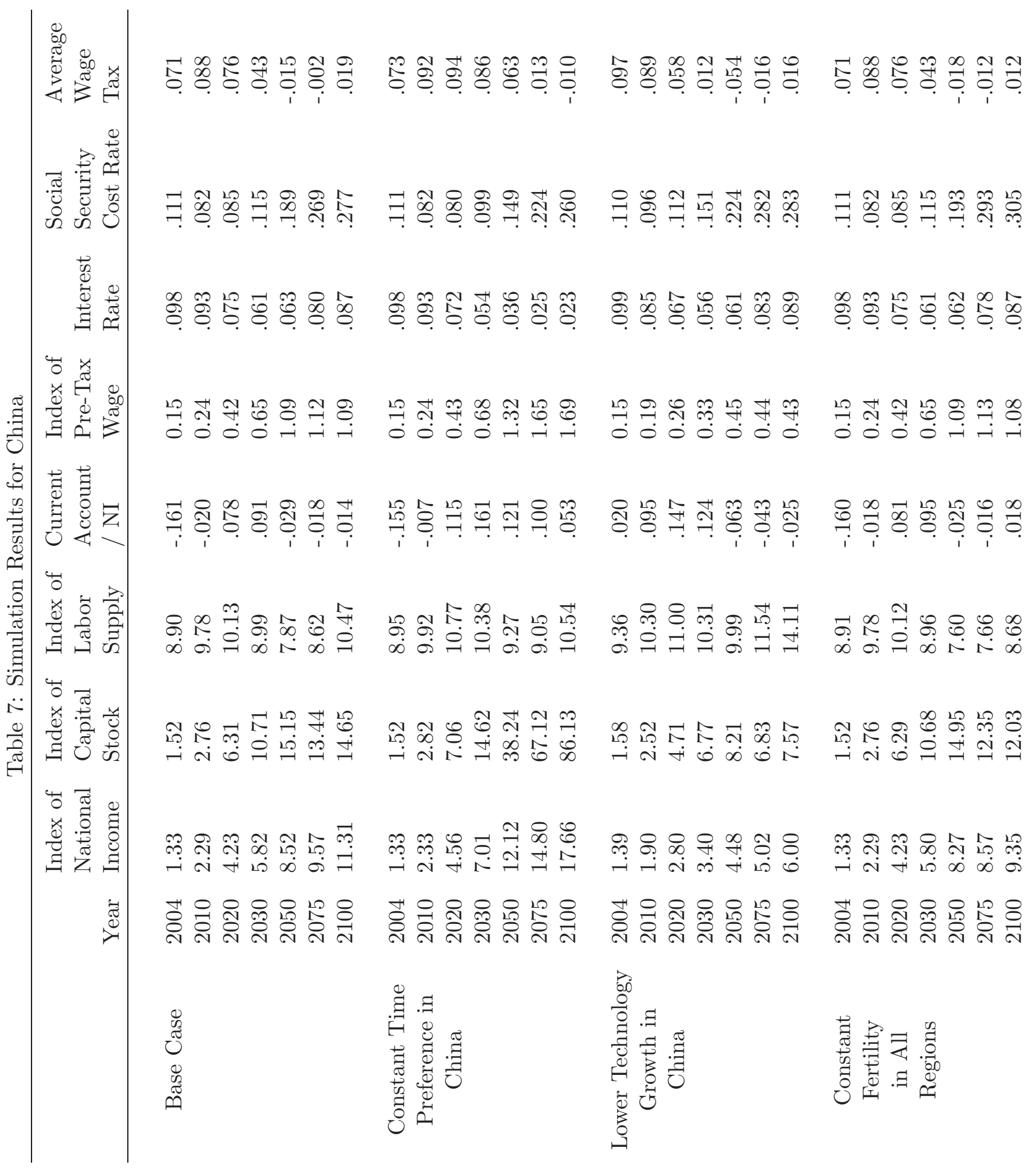




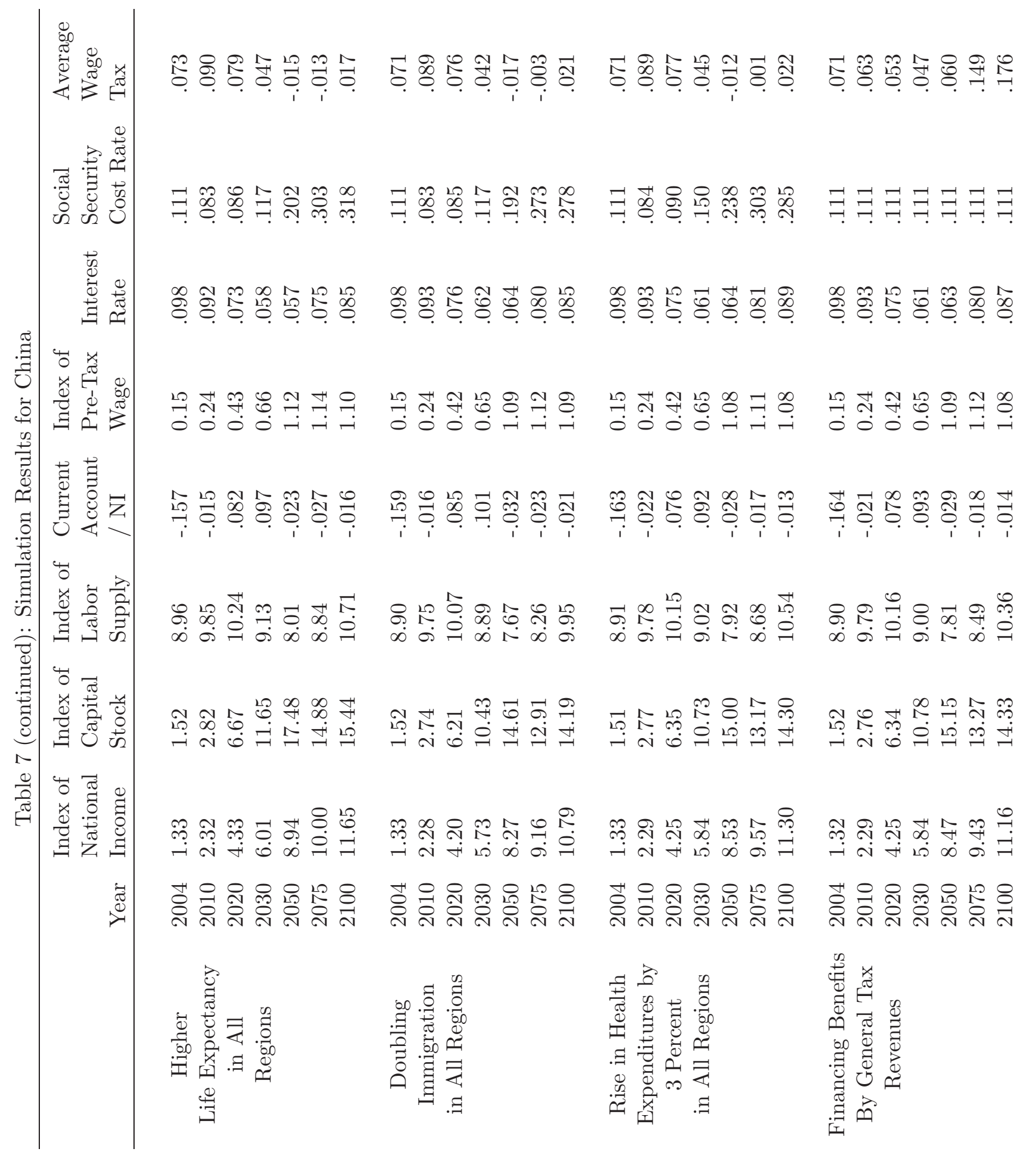




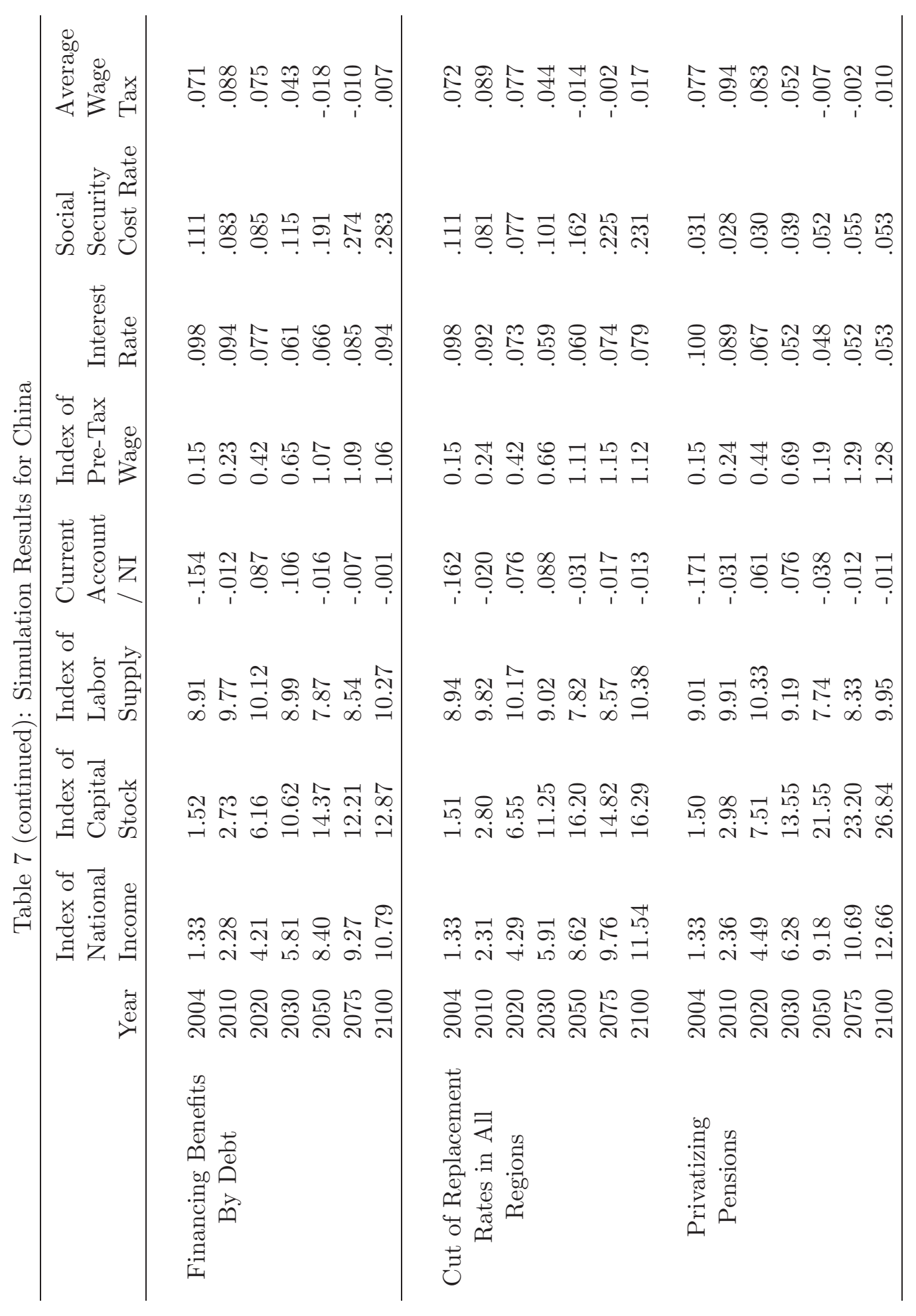




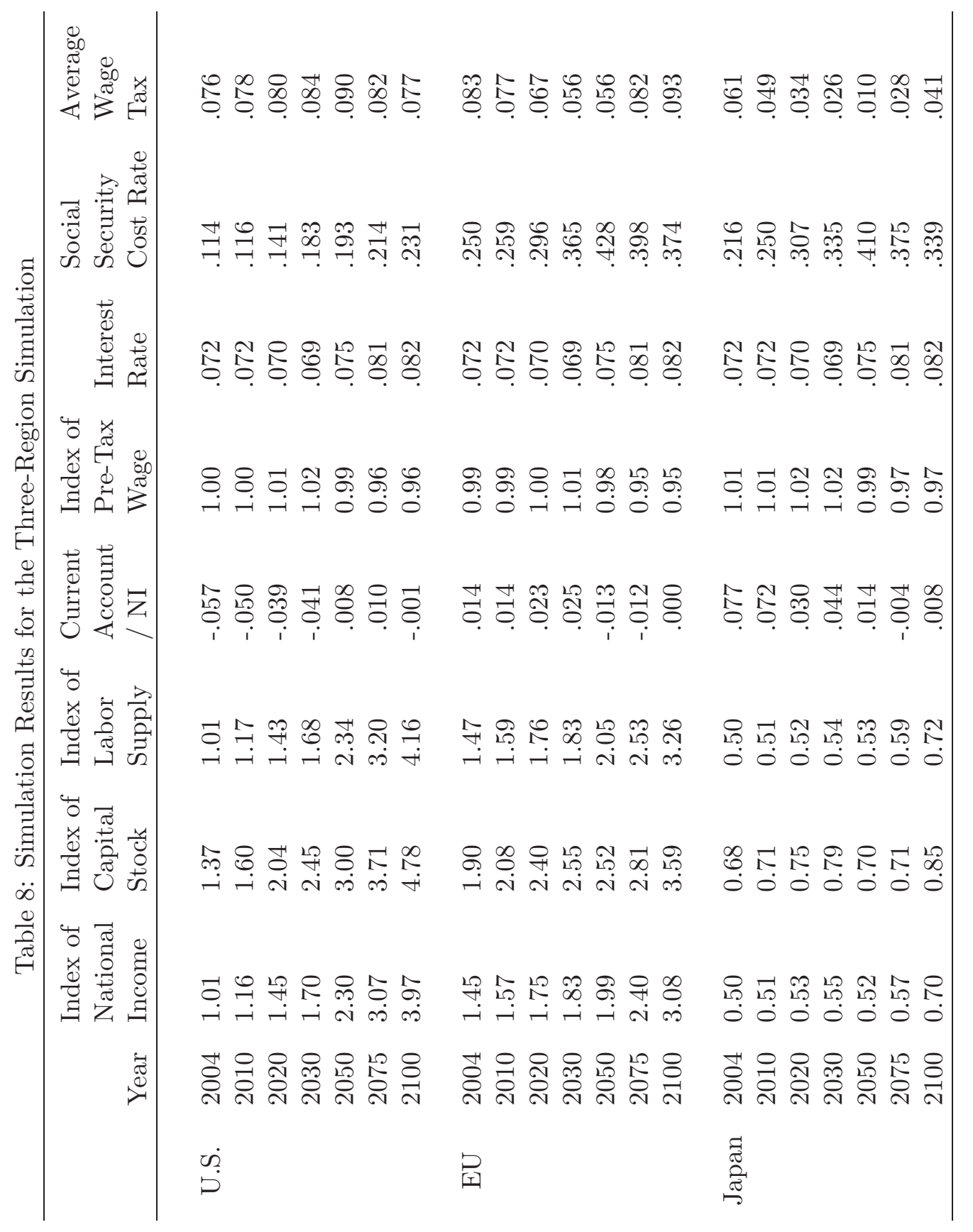




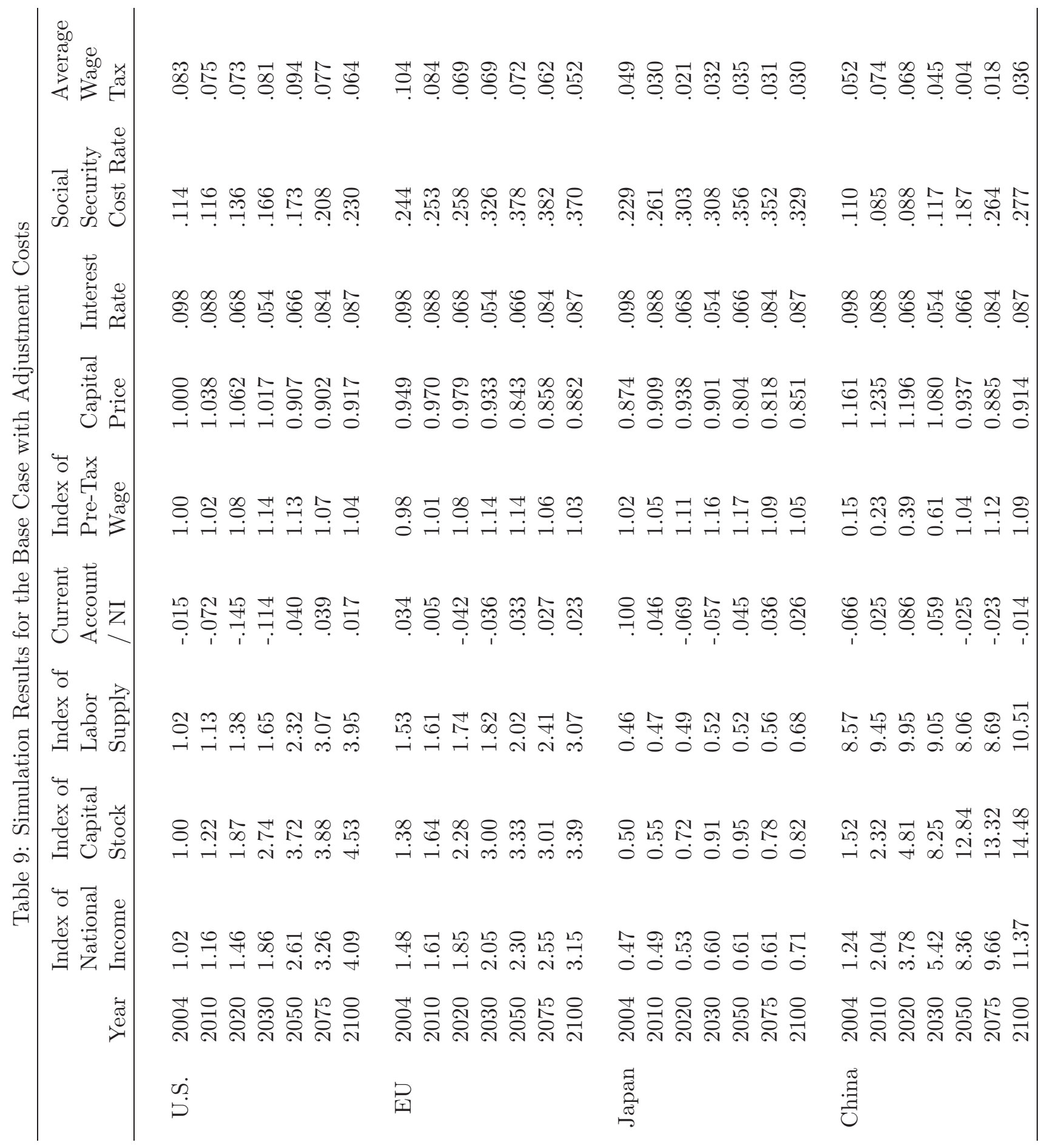


Table 10: Welfare Effects of Lower Technology Growth in China

\begin{tabular}{l|rrr|rrr|rrr|rrr}
\hline & \multicolumn{4}{|c|}{ U.S. } & \multicolumn{3}{c|}{ EU } & \multicolumn{3}{c|}{ Japan } & \multicolumn{4}{c}{ China } \\
Birth & \multicolumn{3}{|c|}{ Income Class } & \multicolumn{3}{c|}{ Income Class } & \multicolumn{3}{c|}{ Income Class } & \multicolumn{3}{c}{ Income Class } \\
Year & 1 & 2 & 3 & 1 & 2 & 3 & 1 & 2 & 3 & 1 & 2 & 3 \\
\hline 1920 & -0.73 & -0.49 & -0.10 & -0.68 & -0.48 & -0.15 & -0.70 & -0.40 & -0.11 & 1.05 & 2.24 & 2.06 \\
1930 & -1.58 & -1.18 & -0.38 & -1.25 & -1.08 & -0.63 & -1.57 & -1.16 & -0.55 & 0.22 & 1.33 & 1.31 \\
1940 & -2.34 & -1.88 & -0.72 & -2.01 & -1.74 & -1.02 & -2.40 & -1.94 & -1.12 & -1.06 & 0.10 & 0.40 \\
1950 & -1.53 & -1.43 & -1.02 & -1.98 & -1.76 & -1.15 & -2.25 & -1.98 & -1.35 & -10.08 & -8.07 & -4.25 \\
1960 & -0.10 & -0.66 & -0.98 & -0.21 & -0.79 & -1.10 & -0.26 & -0.85 & -1.11 & -21.70 & -17.12 & -7.99 \\
1970 & 1.61 & 0.54 & -0.50 & 0.97 & 0.06 & -0.86 & 1.22 & 0.24 & -0.75 & -28.60 & -22.17 & -9.05 \\
1980 & 2.35 & 1.32 & 0.10 & 1.12 & 0.33 & -0.65 & 1.55 & 0.68 & -0.39 & -33.45 & -24.66 & -7.85 \\
1990 & 2.16 & 1.35 & 0.33 & 1.38 & 0.80 & -0.22 & 2.10 & 1.35 & 0.17 & -40.40 & -30.67 & -12.50 \\
2000 & 1.38 & 0.90 & 0.28 & 0.71 & 0.39 & -0.20 & 1.46 & 0.99 & 0.18 & -45.17 & -35.54 & -18.92 \\
2010 & 0.57 & 0.38 & 0.14 & -0.03 & -0.09 & -0.20 & 0.66 & 0.48 & 0.10 & -48.43 & -38.65 & -22.54 \\
2020 & 0.05 & 0.07 & 0.07 & -0.46 & -0.35 & -0.14 & 0.12 & 0.14 & 0.08 & -51.18 & -41.00 & -24.34 \\
2030 & -0.40 & -0.21 & 0.00 & -0.74 & -0.52 & -0.09 & -0.33 & -0.16 & 0.09 & -53.03 & -42.83 & -25.89 \\
\hline
\end{tabular}

Table 11: Welfare Effects of Doubling Immigration in All Regions

\begin{tabular}{l|rrr|rrr|rrrr|rrr}
\hline & \multicolumn{3}{|c|}{ U.S. } & \multicolumn{3}{c|}{ EU } & \multicolumn{3}{c|}{ Japan } & \multicolumn{4}{c}{ China } \\
Birth & \multicolumn{2}{|c|}{ Income Class } & \multicolumn{3}{c}{ Income Class } & \multicolumn{3}{c}{ Income Class } & \multicolumn{3}{c}{ Income Class } \\
Year & 1 & 2 & 3 & 1 & 2 & 3 & 1 & 2 & 3 & 1 & 2 & 3 \\
\hline 1920 & 0.00 & 0.00 & 0.00 & 0.00 & 0.00 & 0.00 & 0.01 & 0.00 & 0.00 & 0.00 & 0.00 & 0.00 \\
1930 & 0.03 & 0.02 & 0.01 & 0.02 & 0.02 & 0.02 & 0.04 & 0.03 & 0.02 & 0.02 & 0.02 & 0.02 \\
1940 & 0.06 & 0.05 & 0.03 & 0.06 & 0.05 & 0.04 & 0.08 & 0.07 & 0.05 & 0.08 & 0.08 & 0.06 \\
1950 & 0.13 & 0.09 & 0.04 & 0.10 & 0.08 & 0.05 & 0.11 & 0.10 & 0.07 & 0.21 & 0.18 & 0.11 \\
1960 & 0.07 & 0.06 & 0.04 & 0.04 & 0.06 & 0.05 & 0.05 & 0.07 & 0.06 & 0.22 & 0.18 & 0.11 \\
1970 & -0.03 & 0.01 & 0.01 & 0.02 & 0.06 & 0.05 & 0.00 & 0.04 & 0.05 & 0.11 & 0.12 & 0.09 \\
1980 & 0.69 & 0.50 & 0.23 & 0.21 & 0.19 & 0.07 & 0.03 & 0.06 & 0.05 & -0.05 & 0.04 & 0.06 \\
1990 & 0.64 & 0.47 & 0.19 & 0.41 & 0.34 & 0.02 & 0.05 & 0.07 & 0.01 & -0.20 & -0.06 & 0.05 \\
2000 & 0.89 & 0.67 & 0.30 & 0.79 & 0.65 & 0.03 & 0.18 & 0.17 & -0.01 & -0.29 & -0.14 & 0.03 \\
2010 & 1.04 & 0.78 & 0.37 & 1.28 & 1.05 & 0.10 & 0.39 & 0.32 & 0.00 & -0.25 & -0.12 & 0.04 \\
2020 & 1.12 & 0.83 & 0.39 & 1.70 & 1.40 & 0.20 & 0.68 & 0.53 & 0.04 & -0.18 & -0.09 & 0.01 \\
2030 & 1.35 & 0.98 & 0.44 & 2.07 & 1.68 & 0.30 & 1.03 & 0.79 & 0.10 & -0.21 & -0.14 & -0.03 \\
\hline
\end{tabular}


Table 12: Welfare Effects of a Rise in Health Expenditures By 3 Percent in All Regions

\begin{tabular}{l|rrr|rrr|rrr|rrr}
\hline & \multicolumn{4}{|c|}{ U.S. } & \multicolumn{4}{c|}{ EU } & \multicolumn{3}{c|}{ Japan } & \multicolumn{4}{c}{ China } \\
Birth & \multicolumn{3}{|c|}{ Income Class } & \multicolumn{3}{c}{ Income Class } & \multicolumn{3}{c}{ Income Class } & \multicolumn{3}{c}{ Income Class } \\
Year & 1 & 2 & 3 & 1 & 2 & 3 & 1 & 2 & 3 & 1 & 2 \\
\hline 1920 & 0.00 & 0.01 & 0.00 & 0.07 & 0.08 & -0.01 & 0.07 & 0.04 & -0.02 & -0.02 & -0.01 & -0.01 \\
1930 & -0.03 & -0.01 & -0.01 & 0.05 & 0.07 & -0.02 & 0.04 & 0.02 & -0.03 & -0.04 & -0.03 & -0.03 \\
1940 & -0.05 & -0.03 & -0.02 & 0.03 & 0.04 & -0.03 & 0.02 & 0.00 & -0.05 & -0.08 & -0.07 & -0.06 \\
1950 & -0.06 & -0.04 & -0.02 & -0.06 & -0.03 & -0.04 & -0.07 & -0.05 & -0.05 & -0.17 & -0.14 & -0.08 \\
1960 & -0.08 & -0.06 & -0.03 & -0.29 & -0.19 & -0.08 & -0.33 & -0.22 & -0.08 & -0.19 & -0.15 & -0.05 \\
1970 & -0.18 & -0.13 & -0.06 & -0.69 & -0.50 & -0.14 & -0.77 & -0.55 & -0.13 & -0.26 & -0.19 & -0.04 \\
1980 & -0.35 & -0.25 & -0.13 & -1.17 & -0.88 & -0.23 & -1.26 & -0.92 & -0.19 & -0.42 & -0.25 & -0.02 \\
1990 & -0.67 & -0.49 & -0.26 & -2.17 & -1.73 & -0.45 & -2.32 & -1.79 & -0.35 & -0.78 & -0.48 & -0.07 \\
2000 & -1.08 & -0.79 & -0.44 & -3.29 & -2.68 & -0.71 & -3.49 & -2.72 & -0.56 & -1.29 & -0.88 & -0.29 \\
2010 & -1.35 & -0.98 & -0.54 & -4.05 & -3.36 & -0.91 & -4.20 & -3.29 & -0.71 & -1.72 & -1.22 & -0.53 \\
2020 & -1.50 & -1.08 & -0.58 & -4.54 & -3.81 & -1.04 & -4.77 & -3.79 & -0.83 & -1.90 & -1.34 & -0.58 \\
2030 & -1.68 & -1.22 & -0.64 & -4.91 & -4.15 & -1.15 & -5.23 & -4.20 & -0.93 & -2.02 & -1.42 & -0.61 \\
\hline
\end{tabular}

Table 13: Welfare Effects of Financing Benefits By General Tax Revenues in All Regions

\begin{tabular}{l|rrr|rrr|rrr|rrrr}
\hline & \multicolumn{4}{|c|}{ U.S. } & \multicolumn{3}{c|}{ EU } & \multicolumn{3}{c|}{ Japan } & \multicolumn{4}{c}{ China } \\
Birth & \multicolumn{3}{|c|}{ Income Class } & \multicolumn{3}{|c}{ Income Class } & \multicolumn{3}{c}{ Income Class } & \multicolumn{3}{c}{ Income Class } \\
Year & 1 & 2 & 3 & 1 & 2 & 3 & 1 & 2 & 3 & 1 & 2 & 3 \\
\hline 1920 & -0.02 & -0.01 & 0.00 & -0.05 & -0.03 & -0.04 & -0.08 & -0.04 & -0.23 & 0.00 & 0.02 & -0.08 \\
1930 & -0.02 & -0.01 & 0.00 & -0.05 & -0.04 & -0.05 & -0.08 & -0.04 & -0.19 & 0.00 & 0.01 & -0.08 \\
1940 & -0.04 & -0.02 & -0.01 & -0.06 & -0.05 & -0.04 & -0.10 & -0.06 & -0.26 & -0.02 & -0.01 & -0.10 \\
1950 & -0.02 & -0.02 & -0.01 & -0.02 & -0.02 & -0.02 & 0.05 & 0.02 & -0.14 & -0.19 & -0.15 & 0.02 \\
1960 & 0.00 & -0.01 & -0.01 & 0.09 & 0.04 & -0.03 & 0.37 & 0.23 & -0.12 & -0.34 & -0.27 & 0.11 \\
1970 & 0.05 & 0.02 & -0.02 & 0.22 & 0.14 & -0.10 & 0.62 & 0.43 & -0.34 & -0.30 & -0.24 & 0.10 \\
1980 & 0.12 & 0.07 & -0.08 & 0.39 & 0.27 & -0.20 & 0.80 & 0.58 & -0.50 & -0.20 & -0.18 & 0.04 \\
1990 & 0.20 & 0.13 & -0.16 & 0.73 & 0.56 & -0.62 & 1.19 & 0.91 & -0.94 & -0.02 & -0.07 & -0.03 \\
2000 & 0.28 & 0.19 & -0.25 & 1.13 & 0.89 & -1.09 & 1.47 & 1.11 & -1.17 & 0.21 & 0.11 & -0.13 \\
2010 & 0.33 & 0.23 & -0.28 & 1.48 & 1.21 & -1.53 & 1.75 & 1.34 & -1.43 & 0.35 & 0.23 & -0.19 \\
2020 & 0.34 & 0.25 & -0.35 & 1.65 & 1.38 & -1.87 & 2.05 & 1.62 & -1.82 & 0.38 & 0.26 & -0.30 \\
2030 & 0.35 & 0.26 & -0.49 & 1.65 & 1.40 & -2.06 & 2.18 & 1.75 & -2.09 & 0.44 & 0.30 & -0.46 \\
\hline
\end{tabular}


Table 14: Welfare Effects of Financing Benefits By Debt

\begin{tabular}{|c|c|c|c|c|c|c|c|c|c|c|c|c|}
\hline \multirow{2}{*}{$\begin{array}{l}\text { Birth } \\
\text { Year }\end{array}$} & \multicolumn{3}{|c|}{$\begin{array}{c}\text { U.S. } \\
\text { Income Class }\end{array}$} & \multicolumn{3}{|c|}{$\begin{array}{c}\text { EU } \\
\text { Income Class }\end{array}$} & \multicolumn{3}{|c|}{$\begin{array}{c}\text { Japan } \\
\text { Income Class }\end{array}$} & \multicolumn{3}{|c|}{$\begin{array}{c}\text { China } \\
\text { Income Class }\end{array}$} \\
\hline & 1 & 2 & 3 & 1 & 2 & 3 & 1 & 2 & 3 & 1 & 2 & 3 \\
\hline 1920 & 0.01 & -0.02 & 0.00 & -0.09 & -0.12 & 0.02 & -0.28 & -0.18 & 0.08 & 0.07 & 0.06 & 0.03 \\
\hline 1930 & 0.09 & 0.05 & 0.02 & -0.04 & -0.07 & 0.06 & -0.19 & -0.09 & 0.10 & 0.13 & 0.12 & 0.08 \\
\hline 1940 & 0.18 & 0.13 & 0.06 & 0.06 & 0.02 & 0.11 & -0.10 & -0.02 & 0.19 & 0.29 & 0.28 & 0.20 \\
\hline 1950 & 0.26 & 0.19 & 0.11 & 0.35 & 0.23 & 0.15 & 0.62 & 0.42 & 0.26 & 0.56 & 0.48 & 0.29 \\
\hline 1960 & 0.43 & 0.31 & 0.17 & 0.83 & 0.60 & 0.27 & 2.27 & 1.53 & 0.44 & 0.46 & 0.39 & 0.24 \\
\hline 1970 & 0.53 & 0.44 & 0.27 & 1.53 & 1.18 & 0.42 & 3.50 & 2.59 & 0.62 & 0.21 & 0.24 & 0.20 \\
\hline 1980 & 0.23 & 0.28 & 0.24 & 0.90 & 0.87 & 0.34 & 1.75 & 1.62 & 0.39 & 0.23 & 0.32 & 0.20 \\
\hline 1990 & -0.07 & 0.10 & 0.18 & 0.06 & 0.32 & 0.07 & -0.62 & 0.00 & -0.39 & -0.02 & 0.17 & 0.22 \\
\hline 2000 & -1.00 & -0.58 & -0.14 & -2.45 & -1.69 & -0.69 & -6.90 & -5.10 & -2.30 & -0.53 & -0.22 & 0.09 \\
\hline 2010 & -3.03 & -2.16 & -1.06 & -7.01 & -5.74 & -2.21 & -15.80 & -12.97 & -5.31 & -1.00 & -0.60 & -0.18 \\
\hline 2020 & -3.55 & -2.52 & -1.22 & -8.56 & -7.11 & -2.85 & -17.05 & -14.03 & -5.95 & -0.93 & -0.49 & -0.05 \\
\hline 2030 & -4.08 & -2.89 & -1.36 & -10.72 & -9.06 & -3.77 & -20.25 & -16.94 & -7.42 & -0.75 & -0.30 & 0.16 \\
\hline
\end{tabular}

Table 15: Welfare Effects of a Cut of Replacement Rates in All Regions

\begin{tabular}{l|rrr|rrr|rrr|rrr|r}
\hline & \multicolumn{4}{|c|}{ U.S. } & \multicolumn{4}{|c|}{ EU } & \multicolumn{4}{c|}{ Japan } & \multicolumn{4}{c}{ China } \\
Birth & \multicolumn{3}{|c|}{ Income Class } & \multicolumn{3}{|c}{ Income Class } & \multicolumn{3}{c}{ Income Class } & \multicolumn{3}{c}{ Income Class } \\
Year & 1 & 2 & 3 & 1 & 2 & 3 & 1 & 2 & 3 & 1 & 2 & 3 \\
\hline 1920 & 0.21 & 0.12 & 0.00 & 0.34 & 0.23 & -0.04 & -0.10 & -0.03 & 0.00 & 0.04 & 0.18 & 0.25 \\
1930 & 0.10 & 0.03 & -0.03 & 0.28 & 0.17 & -0.10 & -0.20 & -0.12 & -0.05 & -0.05 & 0.08 & 0.16 \\
1940 & -0.02 & -0.08 & -0.09 & 0.13 & 0.03 & -0.17 & -0.36 & -0.26 & -0.15 & -0.27 & -0.13 & 0.00 \\
1950 & -2.84 & -1.59 & -0.48 & -3.04 & -1.75 & -0.48 & -0.45 & -0.36 & -0.23 & -3.71 & -3.14 & -1.79 \\
1960 & -1.80 & -1.11 & -0.46 & -2.98 & -1.84 & -0.57 & -0.23 & -0.27 & -0.25 & -3.18 & -2.55 & -1.32 \\
1970 & -0.49 & -0.34 & -0.25 & -1.11 & -0.70 & -0.35 & 0.06 & -0.11 & -0.25 & -1.71 & -1.39 & -0.73 \\
1980 & 0.67 & 0.46 & 0.08 & 0.41 & 0.35 & -0.10 & 0.23 & 0.01 & -0.23 & -0.74 & -0.74 & -0.43 \\
1990 & 1.64 & 1.15 & 0.38 & 2.29 & 1.83 & 0.36 & 0.60 & 0.28 & -0.13 & 0.50 & 0.07 & -0.29 \\
2000 & 2.84 & 1.76 & 0.64 & 4.21 & 3.33 & 0.78 & 0.83 & 0.41 & -0.12 & 2.03 & 1.23 & 0.19 \\
2010 & 3.04 & 2.13 & 0.79 & 5.76 & 4.57 & 1.11 & 0.98 & 0.50 & -0.15 & 3.33 & 2.22 & 0.83 \\
2020 & 3.51 & 2.42 & 0.86 & 6.87 & 5.48 & 1.34 & 1.16 & 0.62 & -0.20 & 3.84 & 2.53 & 0.93 \\
2030 & 4.02 & 2.77 & 0.94 & 7.58 & 6.07 & 1.48 & 1.31 & 0.71 & -0.31 & 4.36 & 2.86 & 1.00 \\
\hline
\end{tabular}


Table 16: Welfare Effects of Privatizing Pensions in All Regions

\begin{tabular}{l|rrr|rrr|rrr|rrr}
\hline & \multicolumn{4}{|c|}{ U.S. } & \multicolumn{4}{c|}{ EU } & \multicolumn{3}{c|}{ Japan } & \multicolumn{4}{c}{ China } \\
Birth & \multicolumn{3}{|c|}{ Income Class } & \multicolumn{3}{c}{ Income Class } & \multicolumn{3}{c}{ Income Class } & \multicolumn{3}{c}{ Income Class } \\
Year & 1 & 2 & 3 & 1 & 2 & 3 & 1 & 2 & 3 & 1 & 2 & 3 \\
\hline 1920 & -4.72 & -2.88 & -1.01 & -8.92 & -6.14 & -3.39 & -8.12 & -5.31 & -2.32 & -7.11 & -6.34 & -4.36 \\
1930 & -5.14 & -3.19 & -1.08 & -9.06 & -6.39 & -3.73 & -8.84 & -5.78 & -2.42 & -6.73 & -6.01 & -4.12 \\
1940 & -5.73 & -3.82 & -1.48 & -9.42 & -6.67 & -3.73 & -9.49 & -6.60 & -3.25 & -7.14 & -6.43 & -4.48 \\
1950 & -6.31 & -4.17 & -2.11 & -9.06 & -6.22 & -3.12 & -6.01 & -4.37 & -2.81 & -9.38 & -8.07 & -5.68 \\
1960 & -4.50 & -3.17 & -2.09 & -5.82 & -4.05 & -3.05 & -1.94 & -1.62 & -2.45 & -8.63 & -7.02 & -4.49 \\
1970 & -1.69 & -1.19 & -1.57 & -2.40 & -1.29 & -2.60 & 0.35 & 0.55 & -2.10 & -7.01 & -5.71 & -3.47 \\
1980 & 1.22 & 1.18 & -0.34 & 0.97 & 1.51 & -1.59 & 2.20 & 2.31 & -1.29 & -5.52 & -4.69 & -2.50 \\
1990 & 3.67 & 2.99 & 0.73 & 5.19 & 5.36 & 0.22 & 4.56 & 4.62 & -0.15 & -2.17 & -2.54 & -2.37 \\
2000 & 7.10 & 5.28 & 1.80 & 11.93 & 10.22 & 1.77 & 8.29 & 7.09 & 0.61 & 5.13 & 2.71 & -0.51 \\
2010 & 10.84 & 7.60 & 2.72 & 19.36 & 15.48 & 3.31 & 12.78 & 9.99 & 1.35 & 12.82 & 8.31 & 2.74 \\
2020 & 14.59 & 9.89 & 3.48 & 26.20 & 20.25 & 4.62 & 17.83 & 13.38 & 2.12 & 17.11 & 10.89 & 3.81 \\
2030 & 18.27 & 12.21 & 4.22 & 30.92 & 23.49 & 5.50 & 21.54 & 15.90 & 2.64 & 21.21 & 13.34 & 4.65 \\
\hline
\end{tabular}

